\title{
A Single Multipurpose FSH-Blocking Therapeutic for Osteoporosis and Obesity
}

\#1Sakshi Gera, ${ }^{\# 1}$ Tan-Chun Kuo, ${ }^{\# 1}$ Funda Korkmaz, ${ }^{1}$ Damini Sant, ${ }^{2}$ Victoria DeMambro, ${ }^{1}$ Anisa Gumerova, ${ }^{1}$ Kathayani Sudha, ${ }^{1}$ Ashley Padilla, ${ }^{3}$ Geoffrey Prevot, ${ }^{3} J a z z$ Munitz, ${ }^{3}$ Abraham

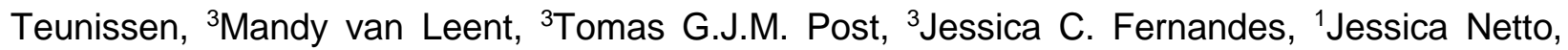
${ }^{1}$ Farhath Sultana, ${ }^{1}$ Eleanor Shelly, ${ }^{1}$ Pushkar Kumar, 'Liam Cullen, ${ }^{1}$ Jiya Chatterjee, ${ }^{1}$ Sari Miyashita, 'Hasni Kannangara, ${ }^{1}$ Megha Bhongade, ${ }^{1}$ Kseniia levleva, ${ }^{1}$ Valeriia Muradova, ${ }^{1}$ Rogerio Batista, ${ }^{1}$ Cemre Robinson, ${ }^{1}$ Anne Macdonald, ${ }^{1}$ Susan Babunovic, ${ }^{4}$ Mansi Saxena, ${ }^{1,4}$ Marcia Meseck, ${ }^{1} J o h n$ Caminis, ${ }^{1}$ Jameel lqbal, ${ }^{1}$ Maria I. New, ${ }^{1}$ Vitaly Ryu, ${ }^{1}$ Se-Min Kim, ${ }^{5}$ Jay J. Cao, ${ }^{6}$ Neeha Zaidi, ${ }^{4}$ Zahi Fayad, ${ }^{1}$ Daria Lizneva, ${ }^{2}$ Clifford J. Rosen, ${ }^{* 1}$ Tony Yuen, ${ }^{* 1}$ Mone Zaidi ("equal contributors; *joint senior authors)

${ }^{1}$ Center for Translational Medicine and Pharmacology and The Mount Sinai Bone Program, Departments of Medicine and of Pharmacological Sciences, Icahn School of Medicine at Mount Sinai, New York, NY 10029, USA; ${ }^{2}$ Maine Medical Center, Research Institute, Scarborough ME 04070, 3BioMedical Engineering and Imaging Institute, Icahn School of Medicine at Mount Sinai, New York, NY 10029, USA; ${ }^{4}$ Tisch Cancer Institute, Icahn School of Medicine at Mount Sinai, New York, NY 10029, USA; 5 United States Department of Agriculture, Grand Forks Human Nutrition Research Center, Grand Forks, ND 58202; ${ }^{6}$ Sidney Kimmel Comprehensive Cancer Center, Johns Hopkins University, Baltimore, MD 21218, USA.

Corresponding author: Mone Zaidi (mone.zaidi@mssm.edu) 


\section{ABSTRACT}

Pharmacological and genetic studies over the past decade have established FSH as an actionable target for diseases affecting millions, notably osteoporosis, obesity and Alzheimer's disease (AD). Blocking FSH action prevents bone loss, fat gain and AD-like features in mice. We recently developed a first-in-class, humanized, epitope-specific FSH blocking antibody, MSHu6, with a $K_{D}$ of $7.52 \mathrm{nM}$. Using a GLP-compliant platform, we now report the efficacy of MSHu6 in preventing obesity and osteoporosis in mice, and parameters of acute safety in monkeys. Biodistribution studies using ${ }^{89} \mathrm{Zr}$-labelled, biotinylated or unconjugated MS-Hu6 in mice and monkeys showed localization to bone, bone marrow and fat depots. MS-Hu6 displayed a $\beta$ phase $\mathrm{t}_{1 / 2}$ of 13 days (316 hours) in humanized Tg32 mice, and bound endogenous FSH. We tested 215 variations of excipients using the protein thermal shift assay to generate a final formulation that rendered MS-Hu6 stable in solution upon freeze-thaw and at different temperatures, with minimal aggregation, and without self-, cross-, or hydrophobic interactions or appreciable binding to relevant human antigens. MS-Hu6 showed the same level of "humanness" as human IgG1 in silico, and was non-immunogenic in ELISPOT assays for IL-2 and IFNy in human peripheral blood mononuclear cell cultures. We conclude that MS-Hu6 is efficacious, durable and manufacturable, and is therefore poised for future human testing as a multipurpose therapeutic. 


\section{INTRODUCTION}

While obesity and osteoporosis are both diseases of public health concern, the paucity of therapies to prevent and treat them continues to represent a challenge $(1,2)$. Accumulating clinical data suggest that the two disorders track together in women across the menopausal transition. Particularly during the late perimenopause, there is precipitous bone loss, onset of visceral obesity, dysregulated energy balance, and reduced physical activity (3-9). These aberrant physiologic changes across the menopausal transition are not fully explained by low estrogen, as estrogen levels are relatively unperturbed, while serum FSH levels rise to maintain estrogen secretion from an otherwise failing ovary (10-12).

The question has been whether a rising FSH level is a driver for post-menopausal obesity and osteoporosis. In 2006, we provided the first evidence for a direct action of FSH on bone (13). Since then, despite controversy fueled mainly from the over-interpretation of clinical studies with $\mathrm{GnRH}$ agonists that suppress not only $\mathrm{FSH}$, but also $\mathrm{GnRH}$ and $\mathrm{LH}(14)$, there is replicable evidence that the selective inhibition of FSH action in mice, for example by using novel $\mathrm{FSH}-$ blocking antibodies or a GST-FSH fusion protein as a vaccine, protects against hypogonadal bone loss (15-19). Serum FSH, bone turnover, and bone mineral density also correlate well in women, particularly when FSH levels are rising during the late perimenopause [review: (20)]. Likewise, activating FSHR polymorphisms in postmenopausal women are linked to a high bone turnover and reduced BMD (21). Thus, it makes both biological and clinical sense to selectively inhibit FSH action to prevent bone loss.

We and our collaborators have also shown that inhibiting FSH by FSH-blocking antibodies reduces white adipose tissue (WAT) in every fat compartment, induces thermogenic (or beige) adipose tissue, and increases energy expenditure in mice (16). Reduced fat mass has also been documented with a vaccine containing tandem repeats of the 13-amino-acid-long FSH receptor- 
binding $\mathrm{FSH} \beta$ sequence to which our antibodies were raised (22). An interventional study in treatment-naïve prostate cancer patients comparing orchiectomy versus triptorelin showed that, with near-zero testosterone, patients on triptorelin (reduced serum FSH and LH) had significantly lower body weight and fat mass compared to those post-orchiectomy (23). Even recognizing the constraints of using a $\mathrm{GnRH}$ agonist, this dataset suggests that lowering serum $\mathrm{FSH}$ could, in principle, have beneficial effects on body composition in people, despite concomitant reductions in $\mathrm{GnRH}$ and $\mathrm{LH}$. There is also new evidence that selective FSH blockade lowers serum total and LDL cholesterol $(24,25)$.

We hypothesize that blocking $\mathrm{FSH}$ action will reduce obesity and bone loss in people. Towards this goal, we have developed our lead candidate, a first-in-class humanized FSHblocking antibody, MS-Hu6. The latter binds a 13-amino-acid-long epitope of human FSH $\beta$ (LVYKDPARPKIQK) with high affinity, and by doing so, blocks the interaction of FSH with its receptor (26). Here, we report a comprehensive characterization of MS-Hu6 in terms of its in vivo efficacy in mouse models of obesity and osteoporosis, acute safety in monkeys, a full evaluation of its pharmacokinetic, pharmacodynamic and biodistribution, and a compendium of its physicochemical properties. This new information provides the framework for first-in-human studies towards the future use of MS-Hu6 in obesity and, osteoporosis.

\section{RESULTS}

\section{Efficacy of MS-Hu6 in Reducing Body Fat and Inducing Beige Adipose Tissue}

In choosing MS-Hu6 as the lead candidate from an array of 30 humanized clones, we examined the electrostatic binding in silico and determined $\mathrm{K}_{\mathrm{D}}$ by surface plasmon resonance in vitro (26). MS-Hu6 had the best affinity $\left(\mathrm{K}_{\mathrm{D}}=7.52 \mathrm{nM}\right)$, approaching that of trastuzumab. We fine mapped the three top candidates to document subtle differences in binding modes (26). In 
addition, we established that MS-Hu6 blocked the binding of labeled recombinant human FSH to the FSHR, and in doing so, inhibited osteoclastogenesis and promoted beiging of adipocytes in vitro (26). Here, we studied the effect of MS-Hu6 on body composition in male ThermoMice fed ad libitum on a high fat diet. Mice were injected with MS-Hu6 or human $\lg$ G $(7 \mu \mathrm{g} /$ day, 5 daysa-week) for 8 weeks. The latter dose was based on the in vitro $\mathrm{IC}_{50}$ of MS-Hu6, which was 30fold lower than our polyclonal Ab (26). We determined net food intake and measured body weight weekly. Of note was a trend towards an increase in food intake in MS-Hu6-treated mice compared with those given human IgG (Fig. 1A). Despite this trend, there was a decline in body weight, with statistically significant decrements at weeks 7 and 8 (Fig. 1A). We also performed quantitative nuclear magnetic resonance (qNMR) at week 8-this revealed a significant decrease in total mass and fat mass with an increase in lean mass (Fig. 1B). This data mimics FSHR haploinsufficiency in male Fshr+- mice (Fig. 1C). Reduced fat mass was notable on manual weighing in the mesenteric, renal, and gonadal compartments-and, expectedly not in brown adipose tissue (BAT) in MS-Hu6-injected mice (Fig. 1D) (16). Quantitative PCR showed evidence for reduced expression of fat genes, namely Pparg, Fabp4 and Cebpa-either significantly or with trends-in subcutaneous and gonadal WAT and BAT (Fig. 1E). Of note is that serum LH, GnRH and testosterone, levels were unchanged after 8 weeks of MS-Hu6, with an unexplained drop in in serum activin (Fig. 1F).

We explored the activation of interscapular BAT and beiging of WAT in vivo by IVIS imaging after 4 and 8 weeks of MS-Hu6 or human IgG treatment. ThermoMice harbor a Luc2T2A-tdTomato dual reporter transgene on the $\mathrm{Y}$ chromosome driven by the Ucp1 promoter (27) (Fig. 2A). Mice were injected with D-Luciferin (150 mg/kg), followed by imaging at 3, 5, 10 and 12 minutes to calculate average radiance. The peak radiance at 10 minutes was higher at 8 weeks, with a trend at 4 weeks in mice receiving MS-Hu6 compared with those given human IgG (Fig. 2B). The upper dorsal interscapular region showed profound BAT activation. WAT beiging 
and BAT activation were both confirmed by UCP1 immunohistochemistry in formalin-fixed, paraffin-embedded sections (Fig. 2C). Of note is that the UCP-1-high beige adipocytes in MSHu6-treated mice appeared highly condensed (Fig. 2C). This effect on cell size was confirmed by morphometry in hematoxylin/eosin stained sections (Fig. 2D). Certain beiging genes, including Ucp1, Cox7 and/or Cidea were upregulated in mice given MS-Hu6, again consistent with whiteto-beige transition (Fig. 2E).

\section{Efficacy of MS-Hu6 in Improving Bone Mass}

We examined the effect of MS-Hu6 on mouse bones in ThermoMice after 8 weeks of MSHu6 or human IgG treatment. Histomorphometry of femoral metaphysis showed significant increases in fractional bone volume (B.Ar/T.Ar) and trabecular thickness (Tb.Th), without an effect on trabecular number (Tb.N) (Fig. 3A). This increase in fractional bone volume was consistent with areal BMD measures (Fig. 3B). Dynamic histomorphometry showed evidence for increased mineral apposition rate (MAR) and bone formation rate (BAR) (Fig. 3C), confirming increased osteoblastic bone formation. In line with a predominately anabolic action of MS-Hu6, the expression of osteoblast genes in bone extracts, such as Col1a1, Alp and Runx2, were either significantly increased or showed trends (Fig. 3D). In contrast, while osteoclast surface (Oc.s/BS) was not reduced, there was a reduction in the expression of the osteoclast marker gene Acp5 (Fig. 3E). The latter finding is not surprising as male ThermoMice mice were not in a high bone turnover state, in which instance a further lowering of bone resorption from baseline would not normally be expected. However, the ex vivo reduction of Acp5 expression suggests that MS-Hu6 was inhibiting the effect of FSH on TRAP-positive osteoclasts.

To further explore the anabolic action of MS-Hu6, and to replicate our dataset in C.J.R.'s lab, 3-month-old female C57BL/6 mice were ovariectomized, followed 24 weeks later by injection of MS-Hu6 or human IgG, daily, at $100 \mu \mathrm{g} /$ day, for 4 weeks and then $50 \mu \mathrm{g} /$ day for a further 4 
weeks. Total body and femoral BMD measured by Piximus was increased significantly in mice treated with MS-Hu6 (Fig. 3F). Micro CT of the femoral epiphysis showed increased BV/TV $(P=0.079)$, Conn.D $(P<0.05)$, and Tb.N $(P=0.057)$, reduced Tb.Sp $(P<0.05)$, and no change in Tb.Th (Fig. 3G). Expectedly, these anabolic effects were not seen in similarly treated $\mathrm{C} 3 \mathrm{H} / \mathrm{HeJ}$ mice, which are known to display a high bone mass phenotype (Supplementary Fig. 1) (28). Overall, therefore, our data show that consistent with previous studies using our polyclonal antibody (17), MS-Hu6 displays an anabolic action in replenishing lost bone.

\section{Pharmacokinetics and Pharmacodynamics of MS-Hu6}

Pharmacokinetic studies were performed in three mouse models-C57BL/6, CD1 and Tg32 mice-using ${ }^{89} \mathrm{Zr}$-labelled, unconjugated, or biotinylated MS-Hu6. For ${ }^{89} \mathrm{Zr}$ labeling, MSHu6 was incubated with the chelator DFO-p-NCS for 3 hours, followed by incubation with ${ }^{89} \mathrm{Zr}$ oxalate for 1 hour at $37^{\circ} \mathrm{C}$, ultrafiltration (cut off $10 \mathrm{kDa}$ ), and thin layer chromatography for quality check (29) (see Methods). ${ }^{89} \mathrm{Zr}-\mathrm{MS}-\mathrm{Hu} 6$ was injected as a single dose of $250 \mu \mathrm{Ci}$ ( 250 $\mu \mathrm{g}$ ) into the retroorbital sinus of $3-$ month-old male C57BL/6 mice ( $N=5$ mice). For $\gamma$-counting few drops of blood were drawn from the tail vein at 5, 30 and 60 minutes, and then at 2, 4, 24, 48, 72 and 120 hours. There was an increase in serum ${ }^{89} \mathrm{Zr}-\mathrm{MS}-\mathrm{Hu} 6$ levels to a $\mathrm{C}_{\max }$ of $29.6 \mu \mathrm{g} / \mathrm{mL}$, which was followed by a gradual decay of radioactivity with a $\beta$ phase $t_{1 / 2}$ of 32 hours (Fig. 4A).

As C57BL/6 mice are inbred strains, we attempted to validate the pharmacokinetic studies in an outbred strain-CD1. The latter mice display genetic diversity reminiscent of the human population, and are used widely for toxicology and efficacy testing (30). For biotinylation, MSHu6 was incubated in the presence of NHS ester-biotin in $\mathrm{NaHCO}_{3}(\mathrm{pH}$ 8) and the product was purified through ultracentrifugation (cut off $10 \mathrm{kDa}$ ) (see Methods). Biotinylated MS-Hu6 (200 $\mu \mathrm{g})$ was injected intraperitoneally with blood sampling by cardiac puncture at 2, 4, 24, 48, 72, 144, 336, 720, and 1440 hours ( $N=3$ mice per time point), and ELISA-based measurements through 
capture by streptavidin-HRP. This yielded a $C_{\max }$ of $63.8 \mu \mathrm{g} / \mathrm{mL}$ and a $\beta$ phase $t_{1 / 2}$ of 41 hours (Fig. 4B).

To enable mouse-to-human comparisons, we studied the pharmacokinetics of MS-Hu6 in Tg32 mice. These mice express the FCGRT transgene encoding the human FcRn receptor on chromosome 2 on a Fcgrt ${ }^{-1}$ background. Tg32 mice show decreased plasma clearance of human IgG-based therapeutics_-thus, more closely mimicking human pharmacokinetics than C57BL/6 mice. We injected 3-month-old male Tg32 mice with ${ }^{89} \mathrm{Zr}-\mathrm{MS}-\mathrm{Hu} 6(\sim 250 \mu \mathrm{Ci}$ or $250 \mu \mathrm{g})$ into the retroorbital sinus followed by sampling at $1,18,24,48,72,144,192,216$ and 240 hours ( $N=5$ mice). Expectedly, the $\beta$ phase $t_{1 / 2}$ increased to 4 days (95 hours), with a $C_{\max }$ of $12.2 \mu \mathrm{g} / \mathrm{mL}$ (Fig. 4C). We further studied the profile of i.p. administered unconjugated MS-Hu6 in Tg32 mice by injecting a single bolus dose of $200 \mu \mathrm{g}$, and measuring human IgG by an in-house sandwich ELISA in which anti-human Fc and Fab were used to capture and detect bound MS-Hu6, respectively ( $N=3$ mice). This yielded $C_{\max }$ of $20 \mu \mathrm{g} / \mathrm{mL}$, with $\beta$ phase $t_{1 / 2}$ of 13 days (316 hours) (Fig. 4D). Of note is that the $\beta$ phase $t_{1 / 2}$ for i.v. trastuzumab, currently in human use, is $\sim 8.5$ days in Tg32 mice (31) — this latter $\beta$ decay translates into 21-day dosing intervals.

We looked for engagement of circulating MS-Hu6 with its target-FSH. For this, we injected groups of male and female C57BL/6 mice, intraperitoneally, with $200 \mu \mathrm{g}$ MS-Hu6 or human IgG. Mice were bled 16 hours later and total IgG (mouse and human) was pulled down using protein A beads. The content of human IgG (control lgG or MS-Hu6) in the eluate, measured by a sandwich ELISA in which plates were coated with anti-human Fc and an antihuman IgG for capture, remained unchanged. We then subjected the same eluate to an sandwich ELISA, in which the plate was coated with anti-human Fc, and the MS-Hu6-FSHßa complex was captured by an antibody to the a subunit of $\mathrm{FSH}$ (incubation at $4^{\circ} \mathrm{C}$, overnight). We found that injected MS-Hu6, but control human IgG bound endogenous FSH in vivo (Fig. 4E). 


\section{Biodistribution and Excretion of MS-Hu6}

To study the biodistribution of ${ }^{89} \mathrm{Zr}-\mathrm{MS}-\mathrm{Hu} 6$, we performed PET-CT scanning of the above treated mice at 24, 48 and 72 hours ( $N=3$ mice). The images show evidence of both decay of circulating radioactivity after 24 hours, and its persistence in multiple organs up to 72 hours (Fig. 5A). Maximal retention in terms of standardized uptake values (SUVs, normalized to muscle) was noted in the liver, with persistence in regions of interest, namely bone marrow, subcutaneous and visceral WAT depots, and the brain region (Fig. 5B). Of note is that these values reflect the presence of ${ }^{89} \mathrm{Zr}-\mathrm{MS}-\mathrm{Hu} 6$ in both blood and tissues.

To determine the extent to which of ${ }^{89} \mathrm{Zr}-\mathrm{MS}-\mathrm{Hu} 6$ persisted in individual tissues, we perfused the mice with $20 \mathrm{~mL}$ PBS before sacrifice and tissue isolation for $\mathrm{y}$-counting. Significant concentrations of ${ }^{89} \mathrm{Zr}-\mathrm{MS}-\mathrm{Hu} 6$ were detected in multiple organs, including bone, bone marrow, subcutaneous WAT, visceral WAT, and BAT (Fig. 5C). Minimal amounts of ${ }^{89} \mathrm{Zr}-\mathrm{MS}-\mathrm{Hu} 6$ were detected in isolated brain tissue at 72 hours - this is consistent with the low penetration of lgGs into the brain ( 0.05 to $0.1 \%$ ) (Fig. $5 \mathrm{C})$. To hone into the early events, we monitored the uptake of ${ }^{89} \mathrm{Zr}-\mathrm{MS}-\mathrm{Hu} 6$ by dynamic PET-CT imaging over 240 minutes. At 10 minutes, radioactivity was detected mainly in large vessels, which was followed at 60 and 240 minutes by permeation into organs (Fig. 5D). As would be expected, radioactivity was not detected in the urine, but instead appeared in the feces (Fig. 5E).

To complement the ${ }^{89} \mathrm{Zr}$-based biodistribution studies, we labelled MS-Hu6 with AlexaFluor-750 (AF750), and injected C57BL/6 mice ( $N=3$ mice) intravenously through the tail vein with AF750-MS-Hu6 (200 $\mu \mathrm{g})$, AF750 alone or PBS. At 16 hours post-injection, anaesthetized mice were imaged using the IVIS platform. We found significant soft tissue distribution of AF750-MSHu6 (Fig. 5F). The mice were then perfused with PBS, followed by IVIS imaging of isolated tissue. Consistent with the ${ }^{89} \mathrm{Zr}$-based studies, there was uptake of AF750-MS-Hu6 by liver, kidney, fat 
depots, bone, and brain (Fig. 5G). In contrast, in the AF750 (dye only) control group, localization was noted only in the kidney due to dye excretion, and not in other organs-in all, confirming organ retention of the AF750-MS-Hu6, and excretion of the unconjugated dye. Because of the expected minimal localization of MS-Hu6 in the brain, we further performed confirmatory studies by immunofluorescence. For this, we injected AF488-MS-Hu6 or unconjugated AF488 into the tail veins of C57BL/6 mice (200 $\mu \mathrm{g}$ permouse). We detected immunofluorescence in liver, kidney and hippocampal sections in mice treated with AF488-MS-Hu6 (Fig. 5H). In contrast, AF488treated mice showed fluorescence in kidney sections, but not in liver or brain (Fig. 5H). Staining of hippocampal sections with an anti-human IgG confirmed localization (Fig. 5I).

To understand MS-Hu6 biodistribution as it may apply to humans, we injected ${ }^{89} \mathrm{Zr}-\mathrm{MS}$ Hu6 as a single bolus dose $(1.3 \mathrm{mg}, \sim 1.3 \mathrm{mCi})$ into the tail veins of two male Cynomolgus monkeys aged 14 and 15 years, respectively. Blood was drawn via tail vein at 5 minutes and at 48 and 120 hours. ${ }^{89} \mathrm{Zr}-\mathrm{MS}-\mathrm{Hu} 6$ peaked in the blood at 5 minutes, with an expected decline, albeit with persistence in the serum, at 48 and 120 hours (Fig. 5J). PET/CT scanning revealed high SUV values in the liver and gall bladder, with lower SUVs in the kidney, spleen, fat depots, bone marrow, and the brain area (Fig. 5K).

\section{Acute and Chronic Safety of FSH Blockade}

We monitored standard safety parameters in treated monkeys up to 100 minutes, and did not observe significant acute or delayed changes post-injection in heart rate, respiratory rate, mean arterial blood pressure, systolic or diastolic blood pressure, or rectal temperature (Fig. 6A). We also drew bloods at day 0 (pre-injection) and at days 2 and 5 post-injection. No concerning deviations from normative values were noted (Fig. 6B). This suggests that, albeit at a low dose, MS-Hu6 as a single intravenous bolus injection into monkeys appeared to be generally safe. 
MS-Hu6 was generated by swapping the mouse framework region of our parent mouse monoclonal antibody Hf2 with the human IgG1 framework, keeping the CDR itself unaltered. While both Fc and Fab region are human, mutations were introduced in the framework flanking the CDR region. Because MS-Hu6 is not fully "human", we first determined its "humanness" in silico by inputting the $\mathrm{V}_{\mathrm{L}}$ and $\mathrm{V}_{\mathrm{H}}$ sequences into abYsis. Comparison of Z-scores revealed a rightshift in comparison with the human-mouse chimeric antibody (26), and in correspondence with human IgG1 (Fig. 6C). In addition, we inputted the primary amino acid sequences of commercially utilized humanized ("zumab") and fully human ("mab") to find that the Z-scores fell in a narrow range away from our chimera or mouse lgGs (Fig. 6C, Table). We next tested immunogenicity experimentally using ELISPOT. The production of inflammatory cytokines IL-2 and IFNy in human peripheral blood mononuclear cell cultures was unaltered by MS-Hu6, in comparison with a standard CEFT peptide pool (positive control, Immunospot) (Fig. 6D). Finally, we provide genetic evidence, using our Fshr+- mouse, that haploinsufficiency of the FSHR-which mimics the effect of FSH blockade on obesity and osteoporosis $(13,15,16)$-does not affect lifespan negatively in male or female mice (Fig. 6E).

\section{Developability, Formulation and Physicochemistry of MS-Hu6}

Therapeutic antibodies selected on the basis of affinity, potency, specificity, functionality and pharmacokinetics might not have unsuitable physicochemical attributes making it difficult to streamline optimal manufacturing. It is therefore imperative that, at an early stage, we determine physicochemical properties, after a rough in silico check for 'red flags' (32-34). We thus used a computational tool, Protein-Sol, based on machine learning of amino acid sequences and physicochemical variables from 48 FDA-approved antibodies and 89 antibodies in late-stage clinical development (https://protein-sol.manchester.ac.uk/abpred) (32-34). In the initial iteration, Protein-Sol provided predicted values for 12 separate physicochemical parameters that 
determine manufacturability. For all outputs, after inputting $\mathrm{V}_{\mathrm{H}}$ and $\mathrm{V}_{\mathrm{L}}$ regions, MS-Hu6 fell within acceptable thresholds, and was therefore deemed to be "safe" (Fig. 7). In essence, the physicochemical properties of MS-Hu6 were likely to be broadly similar to FDA-approved antibodies.

For validation, we inputted a version of MS-Hu6, wherein the CDR region was scrambled- 5 of 12 outputs, namely affinity capture, cross interaction chromatography (CIC), polyspecificity reagent (PSR), expression titers in HEK cells (HEK), and differential scanning fluorescence (DSF), fell outside the respective thresholds-an early indication that the scrambled version was not manufacturable (Fig. 7). In fact, while 65\% FDA-approved monoclonal antibodies show no 'red flags', those with up to 4 red flags have been FDA-approved (34). To complement data from individual outputs, we derived a meta value for both MS-Hu6 and its scrambled sequence ( $1=$ best; $100=$ worst) by averaging ranks for 8 experimental parameters. We found that meta value pairs fell within the lower left quadrant, suggesting overall acceptable physicochemical properties, even in comparison with certain FDA-approved antibodies in the upper right quadrant (Fig. 7).

Before testing the physicochemical characteristics of MS-Hu6 experimentally, we created an optimal formulation. To prevent deamidation and isomerization at neutral and basic $\mathrm{pHs}$, therapeutic antibodies are generally formulated at $\mathrm{pHs}$ away from their isoelectric $\mathrm{pH}(\mathrm{pl})(35,36)$. Using Expasy, we predicted the pl for MS-Hu6 as 8.58. Isoelectric focusing confirmed a pl pf 8.7 (Fig. 8A). We tested 215 combinations of salt, detergent and sugars for their thermal stability (not shown). This yielded in a near-final formulation for MS-Hu6-stock solution of $2 \mathrm{mg} / \mathrm{mL}$ in 20 $\mathrm{mM}$ phosphate, $0.001 \%(\mathrm{v} / \mathrm{v})$ Tween-20, $1 \mathrm{mM} \mathrm{NaCl}$, and $260 \mathrm{mM}$ sucrose $(\mathrm{pH}=6.58)$. We found that both Fc and Fab regions of the formulated MS-Hu6 showed a thermal shift $\left(\Delta T_{m}\right)$ compared with MS-Hu6 in PBS—and, hence, was confirmed as being more stable (Fig. 8B). We also examined the binding of formulated MS-Hu6 to purified human $\mathrm{FSH} . \mathrm{A} \Delta \mathrm{T}_{\mathrm{m}}$ of $3.1^{\circ} \mathrm{C}$ of the Fab, 
and not the Fc region, established greater thermal stability due to $\mathrm{FSH}$ binding (Fig. $8 \mathrm{C}$ ). Furthermore, and of note, is that compared with MS-Hu6 in PBS, formulated MS-Hu6 showed dampened peak signals (Fig. 8B). The latter finding indicates that a lower number of antibody molecules underwent unfolding-implying enhanced stability—despite identical added concentrations $(20 \mu \mathrm{g} /$ well $)$.

For a full physicochemical characterization of the formulated MS-Hu6, we used a battery of biochemical tests, namely $\mathrm{CIC}$, self-interaction chromatography (SIC), size exclusion chromatography (SEC), hydrophobic chromatography, and polyspecificity assays. For CIC and SIC, we created an in-house NHS ester column conjugated either with human IgG (for $\mathrm{CIC}$ ) or MS-Hu6 (for SIC). MS-Hu6 was passed through an unconjugated column both in PBS and as a formulation, as well as through the two conjugated columns. Figs. 8D and 8E show that retention times of MS-Hu6 in the respected conjugated columns were not different from those of the unconjugated column-this confirms that MS-Hu6 does not appreciably interact with itself or with human IgGs, also indicative of little or no aggregation.

Highly soluble and hydrophilic monoclonal antibodies are expected to behave robustly during the manufacturing process. On the other hand, hydrophobic antibodies with high sensitivity to salt may display problems, such as poor expression, aggregation or precipitation during purification. Delayed retention times in a chromatographic assay with a hydrophobic matrix are indicative of a tendency for precipitation. We used a butyl sepharose column, and passed MSHu6 in $1.8 \mathrm{M} \mathrm{NH}_{2} \mathrm{SO}_{4}$ and $0.1 \mathrm{M} \mathrm{Na}_{2} \mathrm{PO}_{4}$ at $\mathrm{pH} 6.5$ over 20 minutes at a flow rate of $1 \mathrm{~mL} / \mathrm{min}$. UV absorbance was monitored at $280 \mathrm{~nm}$ to yield a retention time of 7.1 minutes (Fig. 8F), which is below the theoretical threshold of $11.2 \mathrm{~min}$ (Fig. 7).

We stressed formulated or PBS-containing MS-Hu6 through three freeze-thaw cycles (from $-80^{\circ} \mathrm{C}$ to room temperature), and by incubation for 1 week at $4{ }^{\circ} \mathrm{C}, 37^{\circ} \mathrm{C}$ or $50^{\circ} \mathrm{C}$, followed, 
in all cases, by SEC (Fig. 8G). We noted a major peak (\#4) and three minor high molecular weight peaks (\#1 to 3). Areas under peaks 1 and 2 were between 0 and $0.91 \%$ of the total eluate under all conditions for both PBS-containing and formulated MS-Hu6. Peak 3 remained generally low $(<1.5 \%)$ with formulated MS-Hu6, but was considerably higher (up to 12.7\%) during freeze-thaw in PBS. Furthermore, the major peak 4 was consistently $>99 \%$ with formulated MS-Hu6, particularly when compared to PBS-containing MS-Hu6 under freeze thaw (87.2\%). In all, the formulation protected against aggregation even under extreme stress conditions. Extending the protocol to $25 \mathrm{~mL}$ elution yielded no fragment peaks under any condition (Fig. 8G).

Therapeutic antibodies must undergo a test for polyreactivity to a panel of relevant antigens, including cardiolipin, hemocyanin (KLH), lipopolysaccharide (LPS), double and single stranded DNA, insulin, human albumin, flagellin, and baculovirus particles (BVP). The fold change for MS-Hu6 binding to every molecule in ELISAs, except hemocyanin and BVP, was below a threshold of 3, and was therefore acceptable (Fig. 8H). BVP scores greater than 5 have been shown to enhance antibody clearance, with potential effects on $t_{1 / 2 .}$. In contrast. binding to hemocyanin, an arthropod protein, often used as a carrier for synthetic peptides during immunization (37), was likely due its homology with the 13-amino acid sequence of FSH $\beta$ that binds MS-Hu6 (Fig, 8H). However, as hemocyanin was not used during the production of the parent monoclonal antibody, $\mathrm{Hf} 2$, this is an irrelevant finding. 


\section{DISCUSSION}

Not many biologics, or indeed new therapeutics, undergo robust preclinical evaluations in academic medical centers outside of the pharmaceutical or biotechnology space. Our comprehensive analysis of the biology and physicochemistry of a first-in-class, humanized FSHblocking antibody, MS-Hu6, establishing it as efficacious, safe and manufactureable may arguably be amongst the first attempts at an extensive in-house effort. In 2003, we conceived the idea that pituitary hormones, including $\mathrm{FSH}$, have direct actions on bone (13, 38-40); shifted this new paradigm to establish novel actions of FSH on fat, and more recently, on brain (16, 41); created the first polyclonal FSH-blocking antibody targeted to a 13-amino-acid-long receptor-binding epitope of $\mathrm{FSH} \beta(17,18)$; and finally developed a humanized multipurpose therapeutic (26) for future use in osteoporosis and obesity, and perhaps even in hyperlipidemia and Alzheimer's disease. Notably, the in-house studies described here have been carried out using our own platform that complies with Good Laboratory Practice, as mandated by the Food and Drug Administration's Code of Federal Regulations [Title 21, Chapter 1A, Part 58]. This means, that this Investigational New Drug (IND)-enabling dataset forms the basis of late stage development and future first-in-human studies.

It is now well recognized that targeting the receptor-binding epitope of $\mathrm{FSH} \beta$ to block its interaction with the FSHR inhibits bone resorption, increases bone formation and bone mass, reduces body fat, and enhances thermogenesis $(15-19,22)$. Notably, these effects are triggered not only with our polyclonal and monoclonal FSH-blocking antibodies (15-18), but also through the use by others of vaccines, such as a GST-FSH $\beta$ fusion protein (19) or tandem repeats of the epitope (22). It is also important to note that even with high antibody doses, such as 200 $\mu \mathrm{g} / \mathrm{mouse} /$ day, serum estrogen levels are unchanged $(16,17)$, likely because of the abundance of FSHRs in the ovary that remain responsive to lowered levels of bioavailable FSH. These preclinical data in mice establishing $\mathrm{FSH}$ as an actionable target are reinforced by striking 
estrogen-independent correlations in women between serum $\mathrm{FSH}$, rapid bone loss and visceral obesity during the menopausal transition, at which time serum estrogen is relatively normal and FSH levels are rising $(4,5,9-12)$. This window is likely the most opportune to prevent both bone loss and obesity through selective $\mathrm{FSH}$ blockade. In this regard, while negative data with $\mathrm{GnRH}$ modulators are mostly confounded by concomitant changes in $\mathrm{LH}$ and $\mathrm{GnRH}$ (14), it is clear that low gonadotropin levels in triptorelin-treated men with prostate cancer are associated with lower fat mass and body weight than men undergoing orchiectomy, wherein gonadotropins are high (23). Overall, therefore, the data together lend credibility to the idea that FSH-driven changes, at the very least in body composition, in both sexes can be rescued by blocking $\mathrm{FSH}$. The selective inhibition of FSH action therefore becomes a worthy imperative.

Menopause is also associated with dyslipidemia, which has long been thought to result from estrogen deficiency. However, there is compelling epidemiologic evidence that high serum FSH levels correlate with serum total and LDL cholesterol in post-menopausal women, and importantly, that total cholesterol rises across the perimenopausal transition, essentially tracking closely with bone loss and obesity $(5,7,25,42)$. Impressively, exogenous $\mathrm{FSH}$, in the presence of estrogen clamped at normal levels, increases serum total cholesterol in mice fed on a high cholesterol diet (24). And, consistent with the idea that FSH is an estrogen-independent driver of menopausal hypercholesteremia, an FSH-blocking antibody, which we have previously shown to be active in bone cells, lowers serum cholesterol $(18,24)$. There is also human evidence that reducing serum $\mathrm{FSH}$ by $>30 \%$ from its zenith in post-menopausal women through estrogen replacement therapy lowers serum cholesterol (25). As in the case of bone and fat cells $(13,16)$, hepatocyte FSHRs couple with $\mathrm{Gi}_{2 \alpha}$, which signals through Akt to inhibit FoxO1 binding with the Srebp2 promoter and prevent its repression. Upregulated Srebp2, which drives de novo cholesterol biosynthesis, results in increased cholesterol accumulation and release (24). This action is in addition to the lowering of LDLR expression by FSH (25). Notwithstanding 
cholesterol-lowering mechanism(s), which are likely to be explored even further, it is possible that an FSH-blocking therapeutic, such as MS-Hu6, could have additional actions on lipid metabolism in people.

Furthermore, what underpins the preponderance of Alzheimer's disease (AD) in postmenopausal women, particularly in relation to disease risk, progression and severity, has remained unclear, now for decades. A role for post-menopausal hypoestrogenemia remains controversial, with improvement $(43)$, no change $(44,45)$ or worsening $(46)$ of cognition with estrogen replacement therapy. In contrast, high serum FSH is strongly associated with the onset of $A D$, and has thus been suggested as a possible mediator $(47,48)$. More importantly, certain neuropathologic features, including neuritic plaques, neurofibrillary tangles, and gliosis often begin during the perimenopausal transition (49-53). During this period, women also show a sharp decline in memory function and increased risk of mild cognitive impairment and dementia $(11,52$, 53). We have recently documented exaggerated AD pathology and cognitive decline upon ovariectomy or exogenous FSH injection in three murine models of $A D$, even in the face of estrogen levels clamped in the normal range (41). This phenotype arises from the action of FSH on hippocampal and cortical neuronal receptors using a pathway involving CEBP/ $\beta$ and the $\delta-$ secretase asparagine endopeptidase (41). Most notably, however, we found that our polyclonal FSH-blocking antibody, which shares the target epitope with MS-Hu6 $(17,26)$, prevented the AD-like phenotype induced upon ovariectomy (41)-providing a clear avenue for further exploration of the effects of MS-Hu6 in models of AD.

In all, therefore, we and others have unraveled new actions of FSH that assign it as an actionable target requiring a highly specific approach to block its action in people. We believe that MS-Hu6 with an affinity approaching that of trastuzumab (54), which we have carefully characterized in terms of structure, biological actions, pharmacokinetics, target engagement, biodistribution, safety and manufacturability, is poised for future testing in human trials. 
bioRxiv preprint doi: https://doi.org/10.1101/2022.02 28 482279; this version posted March 2, 2022. The copyright holder for this preprint (which was not certified by peer review) is the author/funder, who has granted bioRxiv a license to display the preprint in perpetuity. It is made available under aCC-BY 4.0 International license.

Admittedly ambitious, we envisage, in a best case scenario, and if mouse data translates into people, of treating four diseases that affect millions of women and men worldwide-namely obesity, osteoporosis, dyslipidemia and neurodegeneration-with a single multipurpose FSHblocking agent. 


\section{ACKNOWLEDGEMENTS}

Work at Icahn School of Medicine at Mount Sinai performed at the Center for Translational Medicine and Pharmacology was supported by R01 AG071870 to M.Z., T.Y. and S.-M.K.; R01 AG074092 and U01 AG073148 to T.Y and M.Z.; U19 AG060917 to M.Z. and C.J.R.; and R01 DK113627 to M.Z. and J.I. Work at U.S. Department of Agriculture, Agricultural Research Service, Grand Forks Human Nutrition Research Center (USDA ARS GFHNRC) was supported by the Project Plan \#3062-51000-053-00D to J.J.C. M.Z. also thanks the Harrington Discovery Institute for the Innovator-Scholar Award towards development of the FSH Ab. C.J.R. acknowledges support from the NIH (P20 GM121301 to C.J.R).

Mention of trade names or commercial products in this publication is solely for the purpose of providing specific information and does not imply recommendation or endorsement by the U.S. Department of Agriculture.

USDA is an equal opportunity provider and employer. The findings and conclusions in this manuscript are those of the authors and should not be construed to represent any official USDA of U.S. Government determination or policy. 


\section{CONFLICTS OF INTEREST}

M.Z. is an inventor on issued patents on inhibiting FSH for the prevention and treatment of osteoporosis and obesity (U.S. Patent $8,435,948$ and $11,034,761$ ). M.Z. is also an inventor on pending patent application on composition and use of humanized monoclonal anti-FSH antibodies, and is co-inventor of a pending patent on the use of FSH as a target for preventing Alzheimer's disease. These patents are owned by Icahn School of Medicine at Mount Sinai (ISMMS), and M.Z. would be recipient of royalties, per institutional policy. M.Z. also consults for several financial platforms, including Gerson Lehman Group and Guidepoint, on drugs for osteoporosis and genetic bone diseases. 


\section{AUTHOR CONTRIBUTIONS}

M.Z., and T.Y. designed the experiments; S.G. performed and/or oversaw most experiments with T.-C.K. and F.K.; D.S., C.R., T.-C.K. and S.G created the and tested the antibody formulation; A.G., S.M. and V.R. carried out histology and histomorphometry; V.D. carried out the bone treatment protocol under C.J.R.'s supervision (Maine Medical Center research Institute, Scarborough, ME); G.P., J.M., J.C.F., T.G.J.M.P., A.T., M.v.L., and Z.F. together with S.G. and T.-C.K. designed and executed experiments involving ${ }^{89} \mathrm{Zr}$ labeling, PET/CT scanning and analyses, and biodistribution and safety studies in monkeys, and J.M. performed PET/CT and PET/MRI data analyses; J.N., E.S., S.G. H.K., K.I. and M.B. assisted with the mouse studies on body composition under the guidance of S.G.; T.-C.K., P.K., A.P., and S.G.. performed biodistribution studies in mice; T.-C.K., F.K. and S.G. carried out pharmacokinetic analyses; J.C. performed the $\mu$ CT data analysis (USDA ARS GFHNRC, Grand Forks, ND) F.S., K.S. and J.N. performed MRI studies; R.B. and V.M. performed studies using Fshr'- mice; S.G. and T.-C.K. performed in silico developability analyses; S.G., D.S. and T.-C.K. performed physicochemical analyses; S.G., N.Z. and T.Y. performed and interpreted in silico immunogenicity and cell proliferation and viability assays; M.S. and M.M. provided regulatory expertise on constructing the GLP platform; L.C. and S.B. drafted protocols using GLP standards; A.M., V.R. and J.I. maintained and provided quality control for the GLP platform; D.L. and S.-M.K. assisted with checking datasets independently and assuring data provenance; J.C. and M.M. provided advice on IND enablement in relation to preclinical studies; M.I.N., C.J.R, T.Y. and M.Z. composed and edited the manuscript. 


\section{METHODS}

\section{Animals}

Colonies of male and female C57BL6 mice, and male $\mathrm{Tg}_{2}$, Fshr ${ }^{+-}$mice, and ThermoMice were obtained from Jackson Labs. Male CD1 mice were from Charles River Laboratories. Mice were maintained in-house at Icahn School of Medicine at Mount Sinai and/or Maine Medical Center Research Institute. They were either fed on normal chow or on a high-fat diet (DIO Formula D12492, 60\% fat; Research Diets, Inc., New Brunswick, NJ.), with access to water ad libitum. The mice were housed in climate-controlled conditions with standard 12-hour light/dark cycles (6 AM to 6 PM). Nonhuman primates, namely Cynomolgus monkeys (Macaca fascicularis), were fed Teklad Global 20\% Protein Primate Diet. All protocols were approved by Institutional Animal Care and Use Committees of Icahn School of Medicine at Mount Sinai and Maine Medical Center Research Institute.

\section{Body Composition}

To study the effects of MS-Hu6 on body composition, we used male SV129 ThermoMice that were allowed ad libitum access to a high-fat diet and injected with MS-Hu6 or human IgG (7 $\mu \mathrm{g} /$ day, 5 days-a-week, i.p.) for 8 weeks. The latter dose was based on the in vitro $\mathrm{IC}_{50}$ of MSHu6, which was $~ 30-$ fold lower than our polyclonal Ab (26). We determined net food intake and measured body weight weekly, and performed quantitative nuclear magnetic resonance (qNMR) at 8 weeks. For this, live mice were placed into a thin-walled plastic cylinder, with freedom to turn around. An Echo3-in-1 NMR analyzer (Echo Medical) was used to measure fat, lean and total mass, per manufacturer.

In ThermoMice, a luciferase reporter construct, Luc2-T2A-tdTomato, is inserted into the Ucp1 locus on the $\mathrm{Y}$-chromosome (55). Activation of Ucp1 expression leads to upregulation of 
Luc2, which can be quantitated in vivo by radiance measurements using IVIS Spectrum In Vivo Imaging System (Perkin Elmer) following the injection of D-Luciferin (150 mg/kg). At 4 and 8 weeks, the mice were injected with D-Luciferin and radiance was captured from dorsal and ventral surfaces for optimal visualization of interscapular (BAT-rich) and inguinal (WAT-rich plus testes) regions, respectively. Isolated fat depots were weighed manually, and RNA extracted for quantitative PCR (qPCR) for fat (Pparg, Fabp4 and Cebpa) and beiging (Ucp1, Cox 8a, Cox7, Cidea, and Prdm16) genes using appropriate primer sets and Prism 7900-HT (Applied Biosystems Inc.) (56).

\section{Histology and Immunodetection Methods}

Tissues were subject to hematoxylin/eosin staining, immunohistochemistry for UCP1 (primary anti-UCP1 antibody: Abcam, Catalog\# ab209483; secondary antibody: goat anti-rabbit IgG, Invitrogen, Catalog\# 32260), or fluorescence for AF488 (conjugated to MS-Hu6) or AF750 (conjugated to human IgG1) [human IgG, Sigma Cataog \# 112511; Alexa Fluor 488 Antibody Labelling Kit, Invitrogen, Catalog \# A20181; SAIVI Rapid Antibody Labelling Kit, Alexa Fluor 750, Invitrogen, Catalog \# S30046]. Frozen brain sections or formalin-fixed, paraffin-embedded sections were examined using an Observer-Z1 microscope (Zeiss, Germany We used the following ELISA kits: FSH and LH (MILLIPLEX MAP Mouse Pituitary Magnetic Beads, Catalog \#: MPTMAG-49K, CLHMAG and RFSHMAG, respectively), testosterone (R and D Systems, Catalog \#: KGE010), and activin A (ThermoFisher, Catalog \# EM3RB).

\section{Bone Phenotyping}

At Maine Medical Center Research Institute, BMD was measured by dual energy X-ray absorptiometry (DXA) (Piximus, Lunar) with a precision of $<1.5 \%$ (57). At Mount Sinai, we used Osteosys iNSIGHT and analyzed the DXA data using Insight v1.0.6. In both instances, 
anaesthetized mice were subject to measurements, with the cranium excluded. The instruments were calibrated each time before use per manufacturer's recommendation.

For $\mu-C T$ measurements, femoral epiphyses were scanned non-destructively by using a Scanco $\mu$ CT scanner ( $\mu$ CT-40; Scanco Medical AG, Bassersdorf, Switzerland) at $12 \mu \mathrm{m}$ isotropic voxel size, with X-ray source power of $55 \mathrm{kV}$ and $145 \mu \mathrm{A}$, and integration time of 300 milliseconds. Trabecular microstructure was evaluated after removing the noise from the scanned grey-scale images using a low-pass Gaussian filter. A fixed bone mineral density threshold of $220 \mathrm{mg} / \mathrm{cm}^{3}$ was used to extract the mineralized bone from soft tissue and the marrow phase. Reconstruction and 3D quantitative analyses were performed using software provided by Scanco. The same settings for scan and analysis were used for all samples. Trabecular bone parameters included fractional bone volume (BV/TV), trabecular thickness (Tb.Th), trabecular number (Tb.N), trabecular spacing (Tb.Sp), and connectivity density (Conn.D).

Two-dimensional histomorphometry was performed in femoral epiphysis. Frozen nondecalcified sections $(6-8 \mu \mathrm{m})$ were stained with a von Kossa staining kit (American MasterTech, Catalog \# KTVKO), per manufacturer's procedure. This provided measures of fractional bone volume (B.Ar/T.Ar), Tb.N, Tb.Sp and Tb.Th. Bone formation was quantified by dynamic histomorphometry following sequential injections of calcein $(15 \mathrm{mg} / \mathrm{kg})$ followed by xylelol orange $(90 \mathrm{mg} / \mathrm{kg})$ eight days apart, with the last injection 4 days prior to sacrifice. Parameters included mineral apposition rate (MAR) and bone formation rate (BFR),. Osteoclast resorbed surface (Oc.S/BS) was measured following TRAP staining with Leukocyte Acid Phosphatase TRAP Kit (Sigma Aldrich, catalog \# 387A-1KT). RNA was extracted from isolated whole femur for qPCR for osteoblast (Col1a1, Alpl, Runx2 and Bglap) and osteoclast (Acp5) genes using appropriate primer sets using Prism 7900-HT (Applied Biosystems Inc.) (56). 


\section{Pharmacokinetics and Biodistribution in Mice}

We prepared ${ }^{89} \mathrm{Zr}-\mathrm{MS}-\mathrm{Hu} 6$ by incubating MS-Hu6 first with the chelator DFO-p-NCS for 3 hours at $37^{\circ} \mathrm{C}$ (in steps of $5 \mu \mathrm{L}$ until a 10-fold molar excess of chelator was achieved). The DFOfunctionalized MS-Hu6 was washed 3 times with PBS in a $10 \mathrm{kDa}$ ultracentrifugation tube before radiolabeling. ${ }^{89} \mathrm{Zr}$-oxalate was diluted with PBS and neutralized with $1 \mathrm{M} \mathrm{Na}_{2} \mathrm{SO}_{4}$ before adding to functionalized MS-Hu6. This was followed by incubation with ${ }^{89} \mathrm{Zr}$-oxalate for 1 hour at $37{ }^{\circ} \mathrm{C}$, ultrafiltration (cut off $10 \mathrm{kDa}$ ), and thin layer chromatography (with $50 \mathrm{mM}$ EDTA) for quality check (29). C57BL/6 or $\mathrm{Tg} 32$ mice were injected in separate experiments with ${ }^{89} \mathrm{Zr}-\mathrm{MS}-\mathrm{Hu} 6$ as a single dose of $\sim 250 \mu \mathrm{Ci}(\sim 250 \mu \mathrm{g}, 250 \pm 40 \mu \mathrm{Ci})$ into the retroorbital sinus. Timed blood (few drops drawn from the tail vein) and excreta collection was followed by weighing and $\mathrm{y}$-counting (PerkinElmer Wizard 2480 Automatic Gamma Counter, PerkinElmer, Waltham, MA). Values were corrected for decay and expressed as a percentage of injected dose per gram of tissue (\%ID/gram).

In complementary experiments, MS-Hu6 was biotinylated by incubating with NHS esterbiotin (100 $\mu \mathrm{g}$ per mg MS-Hu6, dissolved in DMSO, Sigma, Catalog \# H1759) for 4 hours at room temperature. $\mathrm{NaHCO}_{3}(1 \mathrm{M})$ was then added for 10 minutes at room temperature $(\mathrm{pH} 8)$ and the product was purified through ultracentrifugation (cut off $10 \mathrm{kDa}$ ). Biotinylated MS-Hu6 (200 $\mu \mathrm{g}$ ) was injected i.p. into CD1 mice that underwent cardiac puncture for blood sampling and sacrifice at timed intervals. We used an in-house ELISA in which the plate was coated with individual sera and biotinylated MS-Hu6 was captured by streptavidin-HRP (Millipore, Catalog \# 18-152). In a final experiment, unconjugated MS-Hu6 was injected i.p. into Tg32 mice (200 $\mu \mathrm{g})$. Serum was collected from groups of mice and an in-house assay was used in which anti-human IgG Fc (Sigma, Catalog \# FAB3700259) was used to capture human IgG (MS-Hu6), with detection of the complex with goat anti-human IgG Fab (200 $\mu \mathrm{g} /$ well; Invitrogen, \#31122). 
For imaging, ${ }^{89} \mathrm{Zr}-\mathrm{MS}-\mathrm{Hu} 6$-treated mice (above) were anesthetized using $1 \%$ isoflurane in $\mathrm{O}_{2}$ at a flow rate of $\sim 1.0 \mathrm{~L} /$ minute. PET/CT scans were performed using a Mediso nanoScan PET/CT (Mediso, Budapest, Hungary). For whole body CT scans, we used the following parameters: energy, $50 \mathrm{kVp}$; current, $180 \mu \mathrm{As}$; and isotropic voxel size, $0.25 \mathrm{~mm}$ )-this was followed by a 30-min PET scan. Image reconstruction was performed with attenuation correction using the TeraTomo 3D reconstruction algorithm from the Mediso Nucline software (version 3.04). The coincidences were filtered with an energy window between 400 and $600 \mathrm{keV}$. Voxel size was isotropic with $0.4-\mathrm{mm}$ width, and the reconstruction was applied for four full iterations, six subsets per iteration. Image analysis was performed using Osirix MD, version 11.0. Namely, whole body CT images were fused with PET images and analyzed in an axial plane. Regions of interest (ROIs) were drawn on various tissues. Testis, visceral WAT, subcutaneous WAT, kidneys, liver, and brain were traced in their entirety, and bone marrow uptake was assessed using three vertebrae in the lumbar spine. Mean standardized uptake values (SUVs, normalized to muscle) were calculated for each ROI. Subsequently, ${ }^{89} \mathrm{Zr}-\mathrm{MS}-\mathrm{Hu} 6$ uptake of each tissue was expressed as the average of all mean SUV values per organ. After imaging, the mice were sacrificed and perfused with $20 \mathrm{~mL}$ of PBS and tissues of interest, namely brain, heart, kidney, pancreas, liver, lung, bone, bone marrow, BAT, subcutaneous WAT, visceral WAT, adrenal, blood, testis, spleen, and muscle, were isolated for $\mathrm{y}$-counting..

For biodistribution studies using AF750-labelled MS-Hu6, we first imaged the whole body 16 hours after injection using IVIS Spectrum In Vivo Imaging System (Perkin Elmer). Mice were then perfused with PBS, sacrificed and organs, namely heart, thymus, brain, gastronemus and soleus muscle, BAT, adrenals, liver, gall bladder, spleen, kindey, subcutaneous WAT, visceral WAT gonadal WAT, testes and bone were removed and imaged using the same IVIS platform to calculate average radiance efficiency per square area. 


\section{Biodistribution and Safety Studies in Monkeys}

After an overnight fast, two male Cynomolgus monkeys [Scott, aged 14 years, weight 9.8 $\mathrm{kg}$; and Andy, aged 15 years, weight $6.15 \mathrm{~kg}$ ] were anesthetized with ketamine $(5.0 \mathrm{mg} / \mathrm{kg})$ and dexemedetomidine $(0.0075$ to $0.0015 \mathrm{mg} / \mathrm{kg})$. The monkeys were injected with ${ }^{89} \mathrm{Zr}-\mathrm{MS}-\mathrm{Hu} 6$, and blood was drawn at 30 minutes, and at 48 and 120 hours from the tail vein. Vitals, including mean arterial, systolic and diastolic blood pressure, respiratory rate, heart rate and rectal temperature, were recorded using Waveline Touch system (DRE) and Welch Allyn rectal thermometer. PET and MR images were acquired on a combined 3T PET/MRI system (Biograph mMR, Siemens Healthineers). Whole body MR images from each PET bed (head, thorax, pelvis) were automatically collated together with a scanner. MR parameters were as follows: acquisition plane, coronal; repetition time, $1000 \mathrm{~ms}$; echo time, 79 ms; number of slices, 224; number of average, 2; spatial resolution of $0.6 \mathrm{~mm} \times 0.6 \mathrm{~mm} \times 1.0 \mathrm{~mm}$; and acquisition duration, $29 \mathrm{~min}$ and $56 \mathrm{~s}$ per bed. After acquisition, PET raw data from each bed were reconstructed and collated offline using the Siemens proprietary e7tools with an ordered subset expectation maximization (OSEM) algorithm with point spread function (PSF) correction. A dual-compartment (soft tissue and air) attenuation map was used for attenuation. Image analysis was performed using Osirix MD, version 11.0. Whole-body MR images were fused with PET images and analyzed in an axial plane. Regions of interest (ROIs) were drawn on various tissues. The liver, kidney, BAT (interscapular region), subcutaneous WAT, visceral WAT, gonadal WAT, gallbladder, spleen, brain, and testes were traced in their entirety; bone marrow was imaged from the shoulder; and 3 lumbar vertebrae; and muscle was imaged from the quadriceps. Mean SUVs were calculated for each ROI. ${ }^{89} \mathrm{Zr}-\mathrm{MS}-\mathrm{Hu} 6$ uptake of each tissue was expressed as the average of all mean SUV values per organ. Serum was collected for blood chemistry analysis by IDEXX BioAnalytics.

\section{ELISPOT Assay}


Human peripheral blood mononuclear cells (PMBCs, obtained from Immunospot, Cellular Technology Ltd.) were cultured for 12 days in FBS-free DMEM with regular medium change, and plated at a density of $10^{5}$ cells/well in ImmunoSpot ELISPOT plates. Cells were then exposed to MS-Hu6, CEFT or DMEM for 48 hours, following which IL-2 and IFNy expressing cells were quantitated per manufacturer's instructions.

\section{Target Engagement Assays}

For pharmacodynamic studies—namely engagement of MS-Hu6 with FSH as its targetmale and female C57BL/6 mice were injected i.p. with MS-Hu6 or human lgG (200 $\mu \mathrm{g}$, for each). After 16 hours, mice were bled and total IgG (mouse and human) was pulled down using protein A beads (ThermoFisher, Catalog \# 20333). An in-house sandwich ELISA was used to measure human IgG (control IgG or MS-Hu6) in the eluate. For this, plates were coated with anti-human Fc (Sigma, Catalog \# FAB3700259) and goat anti-human HRP-conjugated IgG $(\mathrm{H}+\mathrm{L})$ (Invitrogen, Catalog \# A18805) was used to for capture total human IgG. The same elute then underwent a second in-house sandwich ELISA, in which the plate was coated with anti-human Fc (Sigma, Catalog \# FAB3700259), and after overnight incubation at $4^{\circ} \mathrm{C}$, the MS-Hu6-FSH $\beta \alpha$ complex was captured by an antibody to the a subunit of FSH. In a separate study, a commercial ELISA for FSH (Biotechnology Systems, Catalog \# M7581) was used to determine whether MSHu6 binding to FSH interfered with its detection.

\section{In Silico Analyses}

We used Protein-Sol, a computational algorithm based on machine learning of amino acid sequences and physicochemical variables from 137 antibodies that are FDA-approved or in latestage clinical development (https://protein-sol.manchester.ac.uk/abpred) (32-34). Protein-Sol uses antibody sequences $\left(\mathrm{V}_{\mathrm{H}}\right.$ and $\left.\mathrm{V}_{\mathrm{L}}\right)$ as inputs to provide predicted outputs for clone self- 
interaction by bio-layer interferometry (CSI-BLI), poly-specificity reagent (PSR), baculovirus particle ELISA (BVP-EL), cross-interaction chromatography (CIC), ELISA, accelerated stability (AS), hydrophobic interaction chromatography (HIC), stand-up monolayer adsorption chromatography (SMAC), salt gradient affinity capture (SGAC), expression titer in HEK cells (HEK), affinity capture (AC), and differential scanning fluorescence (DSF). It also provides a meta value for each sequence ( 1 =best; 100=worst) by averaging ranks for 8 experimental parameters. For predicting the pl value MS-Hu6, we inputted its sequence into Expasy (Swiss Bioinformatics Research Portal, https://web.expasy.org/compute pi/). For predicting the "humanness" of humanized MS-Hu6 versus parent chimera and other humanized or fully human molecules (26), we inputted $\quad$ sequences $\quad$ into $\quad$ abYsis $\quad$ (version $\quad$ 3.4.1; http://www.abysis.org/abysis/sequence input/key annotation/key annotation.cgi) to obtain Zscores, and compared the scores with that of $V_{H}$ and $V_{L K}$ chain of $\lg G 1$.

\section{Protein Thermal Shift Assay}

The thermal shift assay used a fluorescent reporter, Sypro-Orange (Protein Thermal Shift Dye Kit, ThermoFisher, Catalog \# 4461146), to detect hydrophobic domains that are exposed following the heat-induced unfolding of globular proteins. MS-Hu6 $(1.5 \mu \mathrm{g} / \mu \mathrm{L})$, formulated or in PBS, was incubated with or without human FSH $(0.5 \mu \mathrm{g} / \mu \mathrm{L})$ at room temperature for 30 minutes, with fluorescence captured sequentially at $0.3^{\circ} \mathrm{C}$ increments using a StepOne Plus Thermocycler (Applied Biosystems). $T_{m}$ was calculated based on the inflection point of the melt curve, and thermal shift was derived from $\Delta T_{m}=T_{m} A-T_{m} B$.

\section{Isoelectric Focusing}

For determining the isoelectric $\mathrm{pH}(\mathrm{pl})$, two dimensional electrophoresis was performed by first rehydrating MS-Hu6 $(500 \mu \mathrm{g})$ for 2 hours at room temperature in rehydration buffer $(8 \mathrm{M}$ urea, 
2\% CHAPS, $0.5 \%$ IPG buffer, and trace of bromophenol blue) without DTT. The sample was then run on an $18 \mathrm{~cm}$ 3-10 strip using the Ettan IPGphor 3 Isoelectric Focusing System (GE Healthcare). Four voltage steps (50 V for 10 hours; $500 \mathrm{~V}$ for 1 hour; $1000 \mathrm{~V}$ for 1 hour; $8000 \mathrm{~V}$ for 4 hours) were followed by Coomassie blue staining.

\section{Chromatography}

An NHS ester column (HiTrap NHS Activated HP, Cytiva, Catalog \# 17071601) was conjugated with either human IgG (for $\mathrm{CIC}$ ) or MS-Hu6 (for SIC) in $0.2 \mathrm{M} \mathrm{NaHCO}_{3}, 0.5 \mathrm{M} \mathrm{NaCl}$ $(\mathrm{pH} 8)$, per manufacturer. Unbound IgG was removed by successive washings $(\mathrm{x} 3)$ at a rate of $0.4 \mathrm{~mL} /$ minute using Buffer $\mathrm{A}(0.5 \mathrm{M}$ ethanolamine, $0.5 \mathrm{M} \mathrm{NaCl}, \mathrm{pH} 8,3)$ and Buffer $\mathrm{B}(0.1 \mathrm{M}$ sodium acetate, $0.5 \mathrm{M} \mathrm{NaCl}, \mathrm{pH}$ 4). An unconjugated column was prepared without including any IgG in the coupling step. MS-Hu6, either as a formulation or in PBS, was run through the unconjugated column, followed by either conjugated columns at $0.2 \mathrm{~mL} / \mathrm{min}$. For SEC, we used a Superdex 200 Increase 10/300 GL (GE Lifesciences, Catalog \# 28990944) and passed MSHu6 (2 mg) in either PBS or formulation buffer after 3 cycles of freeze-thaw or incubation for 1 week at $4{ }^{\circ} \mathrm{C}, 37^{\circ} \mathrm{C}$ or $50^{\circ} \mathrm{C}$. For HIC, we used HiTrap Butyl FF Sepharose column (GE Lifesciences, Catalog \# GE17-1357-01) to run MS-Hu6 at $1 \mathrm{~mL} /$ minute in a linear gradient from 1 $\mathrm{M}$ to $0 \mathrm{M}\left(\mathrm{NH}_{4}\right)_{2} \mathrm{SO}_{4}$ [generated using $1.8 \mathrm{M}\left(\mathrm{NH}_{4}\right)_{2} \mathrm{SO}_{4}$ and $0.1 \mathrm{M} \mathrm{Na}_{2} \mathrm{PO}_{4}(\mathrm{pH}$ 6.5), and $0.1 \mathrm{M}$ $\mathrm{Na}_{2} \mathrm{PO}_{4}(\mathrm{pH}$ 6.5)]. For CIC, SIC, SEC, HIC, absorbance was monitored at $280 \mathrm{~nm}$ using the AKTA PURE FPLC (GE Lifesciences), and the data analyzed by Unicorn version 6.4.

\section{Polyspecificity Testing}

We adapted a previous method to antibody determine polyspecificity (34), and developed an in-house ELISA by coating plates with multiple antigens (50 nM for each), namely double stranded DNA (Shear Salmon Sperm DNA, 5'-3' Inc., Catalog \# 5302-754688), single stranded 
DNA (Deoxyribonucleic acid, single stranded from Calf Thymus, Sigma, Catalog \# D8899), cardiolipin (Cardiolipin sodium salt from bovine heart, Sigma, Catalog \# C0563), LPS-B5 (Lipopolysaccharide E. coli 055:B5, Calbiochem, Catalog \# 437625,), LPS-B4 (LPS-EB, InvivoGen, Catalog \# tlrl-eblps, 50 nM), KLH (keyhole limpet, Hemocyanin from Megathura crenulata, Sigma, Catalog \# H8283), insulin (Humulin R, Lilly, Catalog \# HI213), baculovirus particle (Medna, Catalog \#: E3001), flagellin (Adipogen, Catalog \# AG-4013-0095-C100), human serum albumin (Sigma, Catalog \# A9511) and human pituitary FSH (National Hormone and Pituitary Program, UCLA). The antigens were exposed MS-Hu6 (100 nM), overnight at $4{ }^{\circ} \mathrm{C}$, and any antigen-MS-Hu6 complex was captured by goat anti-human HRP-conjugated IgG (Invitrogen, Catalog \# A18805).

\section{Statistical Methods}

Statistically significant differences between any two groups were examined using a twotailed Student's $t$-test, given equal variance. $P$ values were considered significant at or below 0.05. Data points were excluded if they were 2.5 standard deviations above or below means

Ensuring Rigor and Reproducibility: There is a nascent movement to ensure that preclinical data is true and accurate (58-63). M.Z. and C.J.R. coined the phrase 'contemporaneous reproducibility,' which refers to the synchronous reproduction of data in more than one laboratory. As Zaidi's discovery of the effects of FSH on body fat were novel and unexpected, he reached out to C.J.R. for help in form of a reproducibility study. Key data sets were reproduced by C.J.R in a process that lasted over three years, as other validation studies were added by both laboratories. The term replicability refers to the ability of one or more independent groups to replicate a finding using a different technology or method-replicability is a measure of truth or significance of a given finding(64). Here, we have replicated a key finding that Hu6 increased 
bone mass in the M.Z. and C.J.R. labs, with $\mu$ CT data independently produced by J.C. To further enhance transparency, we have hosted detailed procedures and raw datasets on our GLPcompliant MediaLab Document Control System that all investigators have access to. All data have undergone quality checks before the final product was signed off. Such practices requiring unfettered transparency remain fundamental to ensuring rigor. 


\section{LEGENDS TO FIGURES}

Fiqure 1: MS-Hu6 Reduces Body Weight and Body Fat. Effect of MS-Hu6 or human IgG (7 $\mu \mathrm{g} /$ day, 5 days-a-week) injected i.p. for 8 weeks on food intake and body weight (A), and total mass, fat mass/total mass and lean mass/total mass (by quantitative NMR) (B) in male ThermoMice fed ad libitum on a high fat diet. The effect of MS-Hu6 in reducing body fat mimics the effect of Fshr haploinsufficiency in $\mathrm{Fshr}^{+/-}$mice (C). Weight-based measurements of white adipose tissue in various compartments, namely mesenteric (mWAT), subcutaneous (sWAT), renal (rWAT) and gonadal (gWAT), as well as interscapular brown adipose tissue (BAT) (D). Quantitative PCR showing the expression of fat genes, namely Pparg, Fabp4 and/or Cebpa were reduced in sWAT, gWAT and/or BAT (E). Serum $\mathrm{LH}, \mathrm{GnRH}$, testosterone, activin A and total inhibin levels (F). Statistics: mean \pm s.e.m.; $N=9$ mice/group for panels $A, B$ and $D ; N=3$ mice/group for panel C; 4 to 5 biological replicates for panel E; N=7-9 mice/group for panel F; ${ }^{\star} P<0.05,{ }^{*} P<0.01$.

Figure 2: MS-Hu6 Induces Beiging of White Adipose Tissue. (A) Transgenic construct of Luc2-T2A-tDtomato under control of the Ucp1 promoter. (B) Effect of MS-Hu6 or human IgG (7 $\mu \mathrm{g} /$ day, 5 days-a-week, i.p.) in male ThermoMice fed ad libitum on a high fat diet on emitted radiance from dorsal or ventral surfaces after 4 and 8 weeks post-injection following D-Luciferin (IVIS, 10 minute peak, average radiance, Ctrl: non-transgenic mice given D-Luciferin). (C) UCP1 immunohistochemistry of subcutaneous (sWAT) and gonadal white adipose tissue (gWAT) and brown adipose tissue (BAT). (D) Hematoxylin-eosin staining of WAT showing cell condensation in MS-Hu6-treated mice, measured morphometrically as average (Avg) diameter. Quantitative PCR showing increased expression of beiging genes, namely Ucp1, Cox8a, Cox 7, Cidea and/or Prdm16 in sWAT, gWAT and/or BAT in MS-Hu6-treated mice. Statistics: mean \pm 
s.e.m.; $N=7$ and 9 mice/group for panels $B$ and $D$, respectively; 4 to 5 biological replicates for panel E; ${ }^{*} P<0.05,{ }^{* *} P<0.01,{ }^{* *} P<0.001$, and as shown.

\section{Figure 3: MS-Hu6 Stimulates New Bone Formation and Increases Bone Mass. (A)}

Representative images of von Kossa-stained femoral epiphyses of male ThermoMice mice that were treated with MS-Hu6 or human IgG (7 $\mu \mathrm{g} /$ day, 5 days-a-week, i.p.) and fed ad libitum on a high fat diet. Two-dimensional histomorphometric parameters showing bone volume (B.Ar/T.Ar), and trabecular thickness (Tb.Th) and number (Tb.N). The increase in B.Ar/T.Ar was confirmed on BMD measurements in live mice (B). Dynamic histomorphometry showing representative images of double-labelled sections and quantitative data on mineral apposition rate (MAR) and bone formation rate (BFR). (D) Quantitative PCR showing the expression of osteoblastogenesis genes, namely Bglap, Col1a1, Alpl and Runx2. (E) Osteoclast surfaces (Oc.S.) remained unchanged, but with a reduction in Acp5 (TRAP) gene expression. Parallel studies carried out at C.J.R.'s lab used 3-month-old ovariectomized C57BL/6 mice, which were injected 24 weeks post-ovariectomy with MS-Hu6 or human $\operatorname{lgG}$, daily, at $100 \mu \mathrm{g} / \mathrm{day}$, for 4 weeks and then 50 $\mu \mathrm{g} / \mathrm{day}$ for 4 weeks. Shown are Piximus measurements of total body and femur bone mineral density (BMD) (F), as well as $\mu \mathrm{CT}$ images and quantitative estimates of fractional bone volume (BV/TV), trabecular number (Tb.N), spacing (Tb.S.) and thickness (Tb.Th), and connectivity density (Conn.D) (performed at J.C.'s lab). Statistics: mean \pm s.e.m.; $N=7,8$ mice/group for panel A; $N=9$ mice/group for panel B; $N=9,8$ mice/group for panel C; 4 biological replicates for panel D; $N=7$ mice/group and 4 biological replicates for the left and right bar graphs, respectively, for panel E; $N=11$ and 10 mice/group for panel $\mathrm{F}$ and $\mathrm{G}$, respectively; ${ }^{\star} P<0.05,{ }^{* \star} P<0.01,{ }^{* \star} P<0.001$, and as shown.

Fiqure 4: Pharmacokinetics and Target Engagement of MS-Hu6. Plasma levels, $C_{\max }$ and $\beta$ phase $\mathrm{t}_{1 / 2}$ values for MS-Hu6 injected into C57BL/6 mice $\left(250 \mu \mathrm{Ci}\right.$ of ${ }^{89} \mathrm{Zr}-\mathrm{MS}-\mathrm{Hu}, \mathrm{N}=5$ mice 
followed longitudinally) (A), CD1 mice (200 $\mu$ g biotinylated MS-Hu6, N=3/time point) (B), Tg32 mice $\left(250 \mu \mathrm{Ci}\right.$ of ${ }^{89} \mathrm{Zr}-\mathrm{MS}-\mathrm{Hu} 6, \mathrm{~N}=5$ mice followed longitudinally) (C) and Tg32 mice (200 $\mu \mathrm{g}$ unconjugated MS-Hu6, N=3/time point) (D). (E) Endogenous murine FSH in male and female mouse serum bound to injected MS-Hu6 versus that bound to control human $\lg$ (hlgG). Detection of the MS-Hu6-FSHß $\alpha$ complex was achieved using an in-house ELISA in which the plate was coated with anti-human Fc and the complex captured by an antibody to the $\alpha$ subunit of $\mathrm{FSH}$ ( $N=3$ biologic replicates). Of note is that total human IgG (control lgG or MS-Hu6) captured by an in-house ELISA was not different across treatment groups (E, Table).

Figure 5: Biodistribution and Excretion of MS-Hu6 in Mice and Monkeys. Representative PET-CT images of mice treated with a single bolus dose of ${ }^{89} \mathrm{Zr}$-labeled MS-Hu6 (250 $\left.\mu \mathrm{Ci}\right)$ at 24 , 48 and 72 hours (A), together with quantitation in terms of standardized value uptake units (SUVs, normalized to muscle) in different organs $(N=5,4$ and 2 mice for the three time points, respectively) (B). ${ }^{89} \mathrm{Zr}-\mathrm{MS}-\mathrm{Hu} 6$ ( $\mathrm{Y}$-counts) in individual tissues isolated following perfusion of the mice with $20 \mathrm{~mL}$ PBS ( $N=5,4$ and 5 mice for the three time point, respectively) (C). Dynamic PET/CT images showing the uptake of ${ }^{89} \mathrm{Zr}-\mathrm{MS}-\mathrm{Hu} 6$ over 240 minutes (D). Time course of excretion of ${ }^{89} \mathrm{Zr}$-labelled MS-Hu6 in feces ( $N=5$ mice/time point) (E). Emitted whole body radiance on IVIS imaging of C57BL/6 mice injected with AF750-MS-Hu6 (200 $\mu \mathrm{g})$ or PBS (F). IVIS imaging and quantitation (average radiance) of isolated perfused tissues, as shown. following AF750-MS-Hu6, AF750 or PBS injection ( $N=3$ mice/group) (G). Immunofluorescence micrographs of hippocampal, kidney and liver sections from C57BL/6 mice injected with AF488MS-Hu6 or unconjugated AF488 (200 $\mu \mathrm{g} /$ mouse, i.v.) (H). Counterstaining with an anti-human IgG confirmed localization (I). Whole body PET/CT image, quantitation (SUVs) of multiple organs and serum radioactivity ( $\mathrm{\gamma}$-counts) following a single i.v. injection of ${ }^{89} \mathrm{Zr}-\mathrm{MS}-\mathrm{Hu} 6$ ((1.3 mg, 1.3 $\mathrm{mCi})$ ) in two Cynomolgus monkeys aged 14 and 15 years, respectively (J). 
Figure 6: Acute and Chronic Safety of MS-Hu6. Effects on physiological parameters (monitored up to 100 minutes (A) and serum biochemistry (at days 0, 2 and 5) (B) after injecting ${ }^{89} \mathrm{Zr}$-MS-Hu6 as a single i.v. bolus dose $(1.3 \mathrm{mg}, \sim 1.3 \mathrm{mCi})$ into the tail veins of Cynomolgus monkeys (Andy, 14 years $/ 9.8 \mathrm{~kg}$, and Scott, 15 years $/ 6.15 \mathrm{~kg}$ ). Normative serum biochemistry data (green) from: (65). In silico assessment of "humanness" using abYsis, with Z-scores comparing humanized MS-Hu6, mouse-human chimeric antibody (26), and human IgG1 (C). Table shows narrowly distributed Z-scores after inputting primary sequences of FDA-approved, clinically-utilized humanized ("zumab") and fully human ("mab") antibodies: bevacizumab (antiVEGF, Avastin $\left.{ }^{\circledR}\right)$; trastuzumab (anti-Her2, Herceptin ${ }^{\circledR}$ ); atezolizumab (anti-PD-L1, Tecentrig®); adalimumab (anti-TNFa, Humira®); alirocumab (anti PCSK9, Praluent ${ }^{\circledR}$ ); and canakinumab (anti-IL- $\beta$; Ilaris $®)$ (C). Assessment of immunogenicity using ELISPOT assays for the inflammatory cytokines IL-2 and IFNy in human peripheral blood mononuclear cell cultures in response to added MS-Hu6, DMEM (Ctrl), or CEFT peptide pool (positive control, Immunospot) (D). Kaplan-Meier survival curves showing that haploinsufficiency of Fshr, which otherwise mimics the effect of MS-Hu6 on body fat and bone mass (c.f. Fig. 1C) $(13,16)$ does not reduce lifespan compared with wild type littermates over 1100 days (3 years) (5, 10 mice for wild type male and female, and 23, 22 mice for male and female $\mathrm{Fshr}^{+-}$mice, respectively) (E).

Figure 7: Manufacturability of MS-Hu6. (A) Protein-Sol was used to compare twelve physicochemical parameters that were computationally-derived for MS-Hu6 against experimental derivations of 48 FDA-approved antibodies and 89 antibodies in late-stage (phase 2/3) clinical development. MS-Hu6 fell within the "safe" range and was therefore considered manufacturable. A variation of MS-Hu6, in which the CDR region was scrambled, failed 5 of 12 outputs, indicating non-manufacturability. While 65\% FDA-approved monoclonal antibodies show no 'red flags', those with up to 4 red flags have been approved by the FDA (34). Also shown are meta values for both MS-Hu6 and its scrambled sequence (1=best; 100=worst) derived by averaging ranks for 
8 experimental parameters. MS-Hu6 fell within the lower left quadrant, confirming that physicochemical properties were acceptable for manufacturing.

Figure 8: Physicochemical Characteristics of MS-Hu6. Isoelectric focusing confirmed a pl pf 8.7 for MS-Hu6, consistent with its in silico prediction (Expasy) of 8.58 (A). Thermal shift assays were used to examine stability of both Fc and Fab regions of formulated MS-Hu6 versus MS-Hu6 in PBS (B), as well as stability of FSH binding to the Fab region of formulated MS-Hu6 (C). UV absorbance $(280 \mathrm{~nm})$ readout of self-interaction chromatography (SIC) (D) or cross-interaction chromatography $(\mathrm{CIC})(\mathrm{E})$ to assess binding of formulated MS-Hu6 versus MS-Hu6 in PBS with self or human IgG, respectively. Hydrophobic chromatography showing UV absorbance (280 $\mathrm{nm}$ ) of the eluate from a butyl sepharose column upon passing MS-Hu6 at $\mathrm{pH} 6.5$ over 20 minutes at a flow rate of $1 \mathrm{~mL} / \mathrm{min}$ (retention time shown) (F). Representative size exclusion chromatograms and area under the peak for MS-Hu6 in PBS or formulated MS-Hu6 following stress testing by 3 cycles of freeze-thaw or incubation at $4{ }^{\circ} \mathrm{C}, 37^{\circ} \mathrm{C}$ and $50^{\circ} \mathrm{C}$ for 1 week (G). Reactivity of MS-Hu6 to a standard panel of antigens, including cardiolipin, hemocyanin (KLH), lipopolysaccharides B4 and B5 (LPSB4 and LPSB5), double and single stranded DNA (dsDNA and ssDNA), insulin, human albumin, flagellin, and baculovirus particles (BVP) (ELISAs) (H). Homology of $\mathrm{KLH}$ with the epitope against which MS-Hu6 was raised, showing identical $\left({ }^{*}\right)$ and conserved (:) amino acid residues $(\mathrm{H})$.

\section{Supplementary Figure 1: Bone Phenotype of the $\mathrm{C} 3 \mathrm{H}$ Mouse is Resistant to Anabolic}

Actions of MS-Hu6. Piximus measurements of total body and femur bone mineral density (BMD)

(A), as well as $\mu \mathrm{CT}$ images (B) and quantitative estimates of fractional bone volume (BV/TV), trabecular number (Tb.N), spacing (Tb.S.) and thickness (Tb.Th), and connectivity density (Conn.D) (C). Experiment performed at C.J.R. lab, with $\mu$ CT analysis independently at J.C's lab. 


\section{REFERENCES}

1. International Osteoporosis Foundation. Osteoporosis - Incidence and burden. https://www.iofbonehealth.org/facts-statistics\#category-13.

2. World Health Organization. Obesity and Overweight. https://www.who.int/news-room/factsheets/detail/obesity-and-overweight.

3. Sowers M, Jannausch ML, Gross M, Karvonen-Gutierrez CA, Palmieri RM, Crutchfield M, and Richards-McCullough K. Performance-based physical functioning in AfricanAmerican and Caucasian women at midlife: considering body composition, quadriceps strength, and knee osteoarthritis. Am J Epidemiol. 2006;163(10):950-8.

4. Sowers M, Pope S, Welch G, Sternfeld B, and Albrecht G. The association of menopause and physical functioning in women at midlife. Journal of the American Geriatrics Society. $2001 ; 49(11): 1485-92$.

5. Sowers M, Zheng H, Tomey K, Karvonen-Gutierrez C, Jannausch M, Li X, Yosef M, and Symons J. Changes in body composition in women over six years at midlife: ovarian and chronological aging. J Clin Endocrinol Metab. 2007;92(3):895-901.

6. Sowers MF, Crutchfield M, Jannausch ML, and Russell-Aulet M. Longitudinal changes in body composition in women approaching the midlife. Ann Hum Biol. 1996;23(3):253-65.

7. Sowers MR, Finkelstein JS, Ettinger B, Bondarenko I, Neer RM, Cauley JA, Sherman S, Greendale GA, and Study of Women's Health Across the N. The association of endogenous hormone concentrations and bone mineral density measures in pre- and perimenopausal women of four ethnic groups: SWAN. Osteoporos Int. 2003;14(1):44-52.

8. Sowers MR, Greendale GA, Bondarenko I, Finkelstein JS, Cauley JA, Neer RM, and Ettinger B. Endogenous hormones and bone turnover markers in pre- and perimenopausal women: SWAN. Osteoporos Int. 2003;14(3):191-7.

9. Sowers MR, Jannausch M, McConnell D, Little R, Greendale GA, Finkelstein JS, Neer $\mathrm{RM}$, Johnston $\mathrm{J}$, and Ettinger B. Hormone predictors of bone mineral density changes during the menopausal transition. J Clin Endocrinol Metab. 2006;91(4):1261-7.

10. Randolph JF, Jr., Sowers M, Bondarenko IV, Harlow SD, Luborsky JL, and Little RJ. Change in estradiol and follicle-stimulating hormone across the early menopausal transition: effects of ethnicity and age. J Clin Endocrinol Metab. 2004;89(4):1555-61.

11. Randolph JF, Jr., Zheng H, Sowers MR, Crandall C, Crawford S, Gold EB, and Vuga M. Change in follicle-stimulating hormone and estradiol across the menopausal transition: effect of age at the final menstrual period. J Clin Endocrinol Metab. 2011;96(3):746-54.

12. Randolph JF, Jr., Sowers M, Gold EB, Mohr BA, Luborsky J, Santoro N, McConnell DS, Finkelstein JS, Korenman SG, Matthews KA, Sternfeld B, and Lasley BL. Reproductive hormones in the early menopausal transition: relationship to ethnicity, body size, and menopausal status. J Clin Endocrinol Metab. 2003;88(4):1516-22.

13. Sun L, Peng Y, Sharrow AC, lqbal J, Zhang Z, Papachristou DJ, Zaidi S, Zhu LL, Yaroslavskiy BB, Zhou H, Zallone A, Sairam MR, Kumar TR, Bo W, Braun J, CardosoLanda L, Schaffler MB, Moonga BS, Blair HC, and Zaidi M. FSH directly regulates bone mass. Cell. 2006;125(2):247-60.

14. Drake MT, McCready LK, Hoey KA, Atkinson EJ, and Khosla S. Effects of suppression of follicle-stimulating hormone secretion on bone resorption markers in postmenopausal women. J Clin Endocrinol Metab. 2010;95(11):5063-8.

15. Ji Y, Liu P, Yuen T, Haider S, He J, Romero R, Chen H, Bloch M, Kim SM, Lizneva D, Munshi L, Zhou C, Lu P, lqbal J, Cheng Z, New MI, Hsueh AJ, Bian Z, Rosen CJ, Sun L, et al. Epitope-specific monoclonal antibodies to FSHbeta increase bone mass. Proc Natl Acad Sci U S A. 2018;115(9):2192-7.

16. Liu P, Ji Y, Yuen T, Rendina-Ruedy E, DeMambro VE, Dhawan S, Abu-Amer W, Izadmehr S, Zhou B, Shin AC, Latif R, Thangeswaran P, Gupta A, Li J, Shnayder V, Robinson ST, 
Yu YE, Zhang X, Yang F, Lu P, et al. Blocking FSH induces thermogenic adipose tissue and reduces body fat. Nature. 2017;546(7656):107-12.

17. Zhu LL, Blair H, Cao J, Yuen T, Latif R, Guo L, Tourkova IL, Li J, Davies TF, Sun L, Bian Z, Rosen C, Zallone A, New MI, and Zaidi M. Blocking antibody to the beta-subunit of FSH prevents bone loss by inhibiting bone resorption and stimulating bone synthesis. Proc Natl Acad Sci U S A. 2012;109(36):14574-9.

18. Zhu LL, Tourkova I, Yuen T, Robinson LJ, Bian Z, Zaidi M, and Blair HC. Blocking FSH action attenuates osteoclastogenesis. Biochem Biophys Res Commun. 2012;422(1):548.

19. Geng W, Yan X, Du H, Cui J, Li L, and Chen F. Immunization with FSHbeta fusion protein antigen prevents bone loss in a rat ovariectomy-induced osteoporosis model. Biochem Biophys Res Commun. 2013;434(2):280-6.

20. Zaidi M, New MI, Blair HC, Zallone A, Baliram R, Davies TF, Cardozo C, lqbal J, Sun L, Rosen CJ, and Yuen T. Actions of pituitary hormones beyond traditional targets. $J$ Endocrinol. 2018;237(3):R83-R98.

21. Rendina D, Gianfrancesco F, De Filippo G, Merlotti D, Esposito T, Mingione A, Nuti R, Strazzullo P, Mossetti G, and Gennari L. FSHR gene polymorphisms influence bone mineral density and bone turnover in postmenopausal women. Eur $J$ Endocrinol. 2010;163(1):165-72.

22. Han X, Guan Z, Xu M, Zhang Y, Yao H, Meng F, Zhuo Y, Yu G, Cao X, Du X, Bu G, Kong $F$, Huang $A$, and Zeng $X$. A novel follicle-stimulating hormone vaccine for controlling fat accumulation. Theriogenology. 2020;148:103-11.

23. Ostergren PB, Kistorp C, Fode M, Bennedbaek FN, Faber J, and Sonksen J. Metabolic consequences of gonadotropin-releasing hormone agonists vs orchiectomy: a randomized clinical study. BJU Int. 2019;123(4):602-11.

24. Guo Y, Zhao M, Bo T, Ma S, Yuan Z, Chen W, He Z, Hou X, Liu J, Zhang Z, Zhu Q, Wang Q, Lin X, Yang Z, Cui M, Liu L, Li Y, Yu C, Qi X, Wang Q, et al. Blocking FSH inhibits hepatic cholesterol biosynthesis and reduces serum cholesterol. Cell Res. 2019;29(2):151-66.

25. Song Y, Wang ES, Xing LL, Shi S, Qu F, Zhang D, Li JY, Shu J, Meng Y, Sheng JZ, Zhou $\mathrm{JH}$, and Huang HF. Follicle-Stimulating Hormone Induces Postmenopausal Dyslipidemia Through Inhibiting Hepatic Cholesterol Metabolism. Journal of Clinical Endocrinology \& Metabolism. 2016;101(1):253-62.

26. Gera S, Sant D, Haider S, Korkmaz F, Kuo TC, Mathew M, Perez-Pena H, Xie H, Chen $H$, Batista R, Ma K, Cheng Z, Hadelia E, Robinson C, Macdonald A, Miyashita S, Williams $A$, Jebian $G$, Miyashita $H$, Gumerova $A$, et al. First-in-class humanized FSH blocking antibody targets bone and fat. Proc Natl Acad Sci U S A. 2020;117(46):28971-9.

27. Galmozzi A, Sonne SB, Altshuler-Keylin S, Hasegawa Y, Shinoda K, Luijten IHN, Chang JW, Sharp LZ, Cravatt BF, Saez E, and Kajimura S. ThermoMouse: an in vivo model to identify modulators of UCP1 expression in brown adipose tissue. Cell Rep. 2014;9(5):1584-93.

28. Bouxsein ML, Myers KS, Shultz KL, Donahue LR, Rosen CJ, and Beamer WG. Ovariectomy-induced bone loss varies among inbred strains of mice. J Bone Miner Res. 2005;20(7):1085-92.

29. van de Watering FC, Rijpkema M, Perk L, Brinkmann U, Oyen WJ, and Boerman OC. Zirconium-89 labeled antibodies: a new tool for molecular imaging in cancer patients. Biomed Res Int. 2014;2014:203601.

30. Annas A, Bengtsson C, and Tornqvist E. Group housing of male CD1 mice: reflections from toxicity studies. Lab Anim. 2013;47(2):127-9. 
31. Low BE, Christianson GJ, Lowell E, Qin W, and Wiles MV. Functional humanization of immunoglobulin heavy constant gamma 1 Fc domain human FCGRT transgenic mice. MAbs. 2020;12(1):1829334.

32. Hebditch M, and Warwicker J. Protein-sol abpred software. https://proteinsol.manchester.ac.uk/abpred.

33. Hebditch M, and Warwicker J. Charge and hydrophobicity are key features in sequencetrained machine learning models for predicting the biophysical properties of clinical-stage antibodies. PeerJ. 2019;7:e8199.

34. Jain T, Sun T, Durand S, Hall A, Houston NR, Nett JH, Sharkey B, Bobrowicz B, Caffry I, Yu Y, Cao Y, Lynaugh H, Brown M, Baruah H, Gray LT, Krauland EM, Xu Y, Vasquez M, and Wittrup KD. Biophysical properties of the clinical-stage antibody landscape. Proc Natl Acad Sci U S A. 2017;114(5):944-9.

35. Goswami S, Wang W, Arakawa T, and Ohtake S. Developments and challenges for mAbbased therapeutics. Antibodies 2013;2(3):452-500.

36. Wang W, Singh S, Zeng DL, King K, and Nema S. Antibody structure, instability, and formulation. J Pharm Sci. 2007;96(1):1-26.

37. Lateef SS, Gupta S, Jayathilaka LP, Krishnanchettiar S, Huang JS, and Lee BS. An improved protocol for coupling synthetic peptides to carrier proteins for antibody production using DMF to solubilize peptides. J Biomol Tech. 2007;18(3):173-6.

38. Abe E, Marians RC, Yu W, Wu XB, Ando T, Li Y, lqbal J, Eldeiry L, Rajendren G, Blair $\mathrm{HC}$, Davies TF, and Zaidi M. TSH is a negative regulator of skeletal remodeling. Cell. 2003;115(2):151-62.

39. Sun L, Lizneva D, Ji Y, Colaianni G, Hadelia E, Gumerova A, levleva K, Kuo TC, Korkmaz F, Ryu V, Rahimova A, Gera S, Taneja C, Khan A, Ahmad N, Tamma R, Bian Z, Zallone A, Kim SM, New MI, et al. Oxytocin regulates body composition. Proc Natl Acad Sci U S A. 2019.

40. Tamma R, Colaianni G, Zhu LL, DiBenedetto A, Greco G, Montemurro G, Patano N, Strippoli M, Vergari R, Mancini L, Colucci S, Grano M, Faccio R, Liu X, Li J, Usmani S, Bachar M, Bab I, Nishimori K, Young LJ, et al. Oxytocin is an anabolic bone hormone. Proc Natl Acad Sci U S A. 2009;106(17):7149-54.

41. Xiong J, Kang SS, Wang Z, Liu X, Kuo T-C, Korkmaz F, Padilla A, Miyashita S, Chan P, Zhang Z, Katsel P, Burgess J, Gumerova A, levleva K, Sant D, Yu S-P, Muradova V, Frolinger T, Lizneva D, lqbal J, et al. FSH Inhibition Improves Cognition in Mice with Alzheimer's Disease. Nature. 2022.

42. van Beresteijn EC, Korevaar JC, Huijbregts PC, Schouten EG, Burema J, and Kok FJ. Perimenopausal increase in serum cholesterol: a 10-year longitudinal study. $A m \mathrm{~J}$ Epidemiol. 1993;137(4):383-92.

43. Matyi JM, Rattinger GB, Schwartz S, Buhusi M, and Tschanz JT. Lifetime estrogen exposure and cognition in late life: the Cache County Study. Menopause. 2019;26(12):1366-74.

44. Zandi PP, Carlson MC, Plassman BL, Welsh-Bohmer KA, Mayer LS, Steffens DC, Breitner $\mathrm{JC}$, and Cache County Memory Study I. Hormone replacement therapy and incidence of Alzheimer disease in older women: the Cache County Study. JAMA. 2002;288(17):21239.

45. O'Brien J, Jackson JW, Grodstein F, Blacker D, and Weuve J. Postmenopausal hormone therapy is not associated with risk of all-cause dementia and Alzheimer's disease. Epidemiol Rev. 2014;36:83-103.

46. Shumaker SA, Legault C, Kuller L, Rapp SR, Thal L, Lane DS, Fillit H, Stefanick ML, Hendrix SL, Lewis CE, Masaki K, Coker LH, and Women's Health Initiative Memory S. Conjugated equine estrogens and incidence of probable dementia and mild cognitive 
impairment in postmenopausal women: Women's Health Initiative Memory Study. JAMA. $2004 ; 291(24): 2947-58$.

47. Short RA, Bowen RL, O'Brien PC, and Graff-Radford NR. Elevated gonadotropin levels in patients with Alzheimer disease. Mayo Clin Proc. 2001;76(9):906-9.

48. Bowen RL, Isley JP, and Atkinson RL. An association of elevated serum gonadotropin concentrations and Alzheimer disease? J Neuroendocrinol. 2000;12(4):351-4.

49. Hampel H, Vergallo A, Giorgi FS, Kim SH, Depypere H, Graziani M, Saidi A, Nistico R, Lista S, and Alzheimer Precision Medicine I. Precision medicine and drug development in Alzheimer's disease: the importance of sexual dimorphism and patient stratification. Front Neuroendocrinol. 2018;50:31-51.

50. Dubois B, Hampel H, Feldman HH, Scheltens P, Aisen P, Andrieu S, Bakardjian H, Benali H, Bertram L, Blennow K, Broich K, Cavedo E, Crutch S, Dartigues JF, Duyckaerts C, Epelbaum S, Frisoni GB, Gauthier S, Genthon R, Gouw AA, et al. Preclinical Alzheimer's disease: Definition, natural history, and diagnostic criteria. Alzheimers Dement. 2016;12(3):292-323.

51. Jack CR, Jr., Knopman DS, Jagust WJ, Petersen RC, Weiner MW, Aisen PS, Shaw LM, Vemuri $P$, Wiste HJ, Weigand SD, Lesnick TG, Pankratz VS, Donohue MC, and Trojanowski JQ. Tracking pathophysiological processes in Alzheimer's disease: an updated hypothetical model of dynamic biomarkers. Lancet Neurol. 2013;12(2):207-16.

52. Epperson CN, Sammel MD, and Freeman EW. Menopause effects on verbal memory: findings from a longitudinal community cohort. J Clin Endocrinol Metab. 2013;98(9):382938.

53. Greendale GA, Huang MH, Wight RG, Seeman T, Luetters C, Avis NE, Johnston J, and Karlamangla AS. Effects of the menopause transition and hormone use on cognitive performance in midlife women. Neurology. 2009;72(21):1850-7.

54. Genentech. In: Administration FaD ed. Herceptin (Package Insert). 1998.

55. Galmozzi A, Sonne SB, Altshuler-Keylin S, Hasegawa Y, Shinoda K, Luijten IH, Chang JW, Sharp LZ, Cravatt BF, Saez E, and Kajimura S. ThermoMouse: an in vivo model to identify modulators of UCP1 expression in brown adipose tissue. Cell reports. 2014;9(5):1584-93.

56. Yuen T, Wurmbach E, Pfeffer RL, Ebersole BJ, and Sealfon SC. Accuracy and calibration of commercial oligonucleotide and custom cDNA microarrays. Nucleic acids research. 2002;30(10):e48.

57. Sun L, lqbal J, Dolgilevich S, Yuen T, Wu XB, Moonga BS, Adebanjo OA, Bevis PJ, Lund F, Huang CL, Blair HC, Abe E, and Zaidi M. Disordered osteoclast formation and function in a CD38 (ADP-ribosyl cyclase)-deficient mouse establishes an essential role for CD38 in bone resorption. FASEB journal : official publication of the Federation of American Societies for Experimental Biology. 2003;17(3):369-75.

58. Ioannidis JP. Why most published research findings are false. PLoS Med. 2005;2(8):e124.

59. Collins FS, and Tabak LA. Policy: NIH plans to enhance reproducibility. Nature. 2014;505(7485):612-3.

60. McNutt M. Reproducibility. Science. 2014;343(6168):229.

61. Mullard A. Cancer reproducibility project yields first results. Nat Rev Drug Discov. 2017;16(2):77.

62. Horrigan SK, Courville P, Sampey D, Zhou F, Cai S, and Reproducibility Project: Cancer B. Replication Study: Melanoma genome sequencing reveals frequent PREX2 mutations. Elife. 2017;6.

63. Horrigan SK, and Reproducibility Project: Cancer B. Replication Study: The CD47-signal regulatory protein alpha (SIRPa) interaction is a therapeutic target for human solid tumors. Elife. 2017;6. 
bioRxiv preprint doi: https://doi org/10.1101/2022 02 28.482279; this version posted March 2, 2022. The copyright holder for this preprint (which was not certified by peer review) is the author/funder, who has granted bioRxiv a license to display the preprint in perpetuity. It is made available under aCC-BY 4.0 International license.

64. Rosen CJ, and Zaidi M. Contemporaneous reproduction of preclinical science: a case study of FSH and fat. Ann N Y Acad Sci. 2017;1404(1):17-9.

65. Koo BS, Lee DH, Kang P, Jeong KJ, Lee S, Kim K, Lee Y, Huh JW, Kim YH, Park SJ, Jin YB, Kim SU, Kim JS, Son Y, and Lee SR. Reference values of hematological and biochemical parameters in young-adult cynomolgus monkey (Macaca fascicularis) and rhesus monkey (Macaca mulatta) anesthetized with ketamine hydrochloride. Lab Anim Res. 2019;35:7. 
bioRxiv preprint doi: https://doi.org/10.1101/2022.02.28.482279; this version posted March 2, 2022. The copyright holder for this preprint (which was not certified by peer review) is the author/funder, who has granted bioRxiv a license to display the preprint in perpetuity. It is made available under aCC-BY 4.0 International license.

Figure 1

A

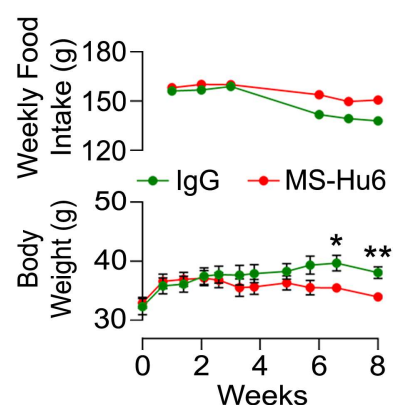

$\mathrm{E}$

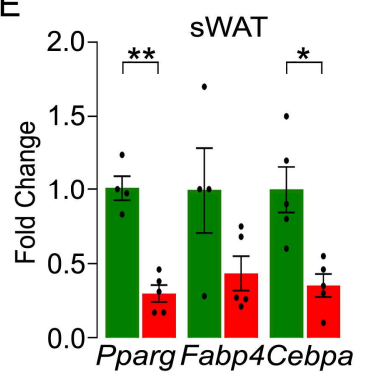

B
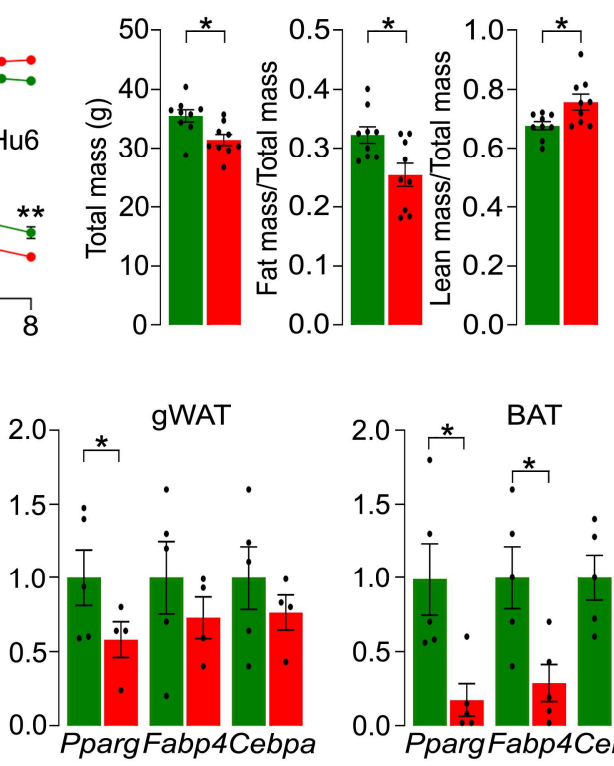

C

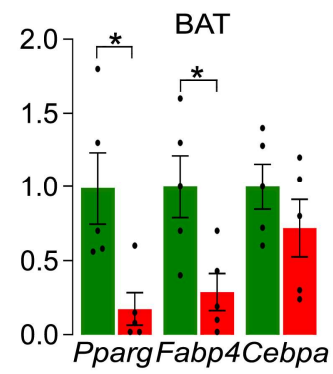

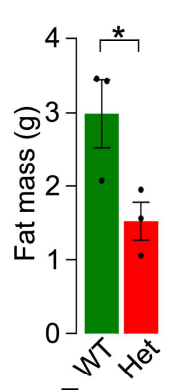

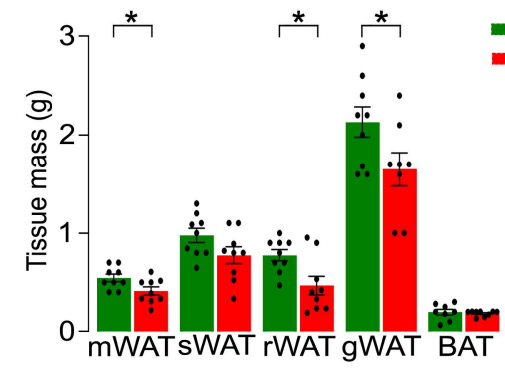

$\mathrm{F}$

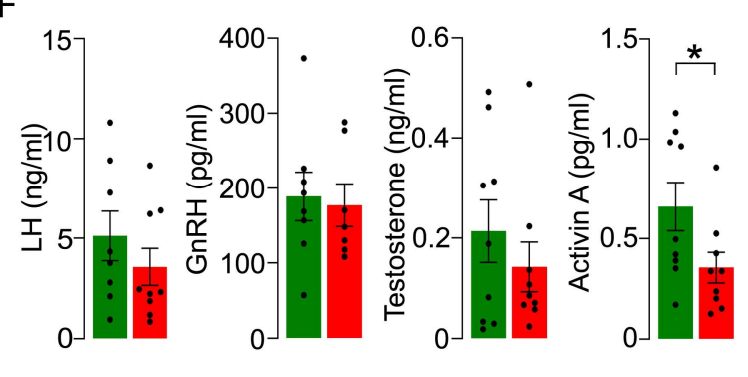


bioRxiv preprint doi: https://doi.org/10.1101/2022.02.28.482279; this version posted March 2, 2022. The copyright holder for this preprint (which was not certified by peer review) is the author/funder, who has granted bioRxiv a license to display the preprint in perpetuity. It is made available under aCC-BY 4.0 International license.

A

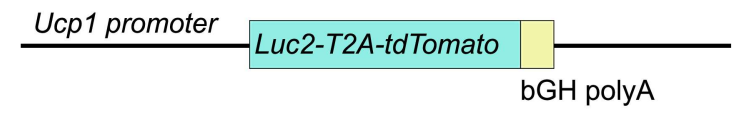

C

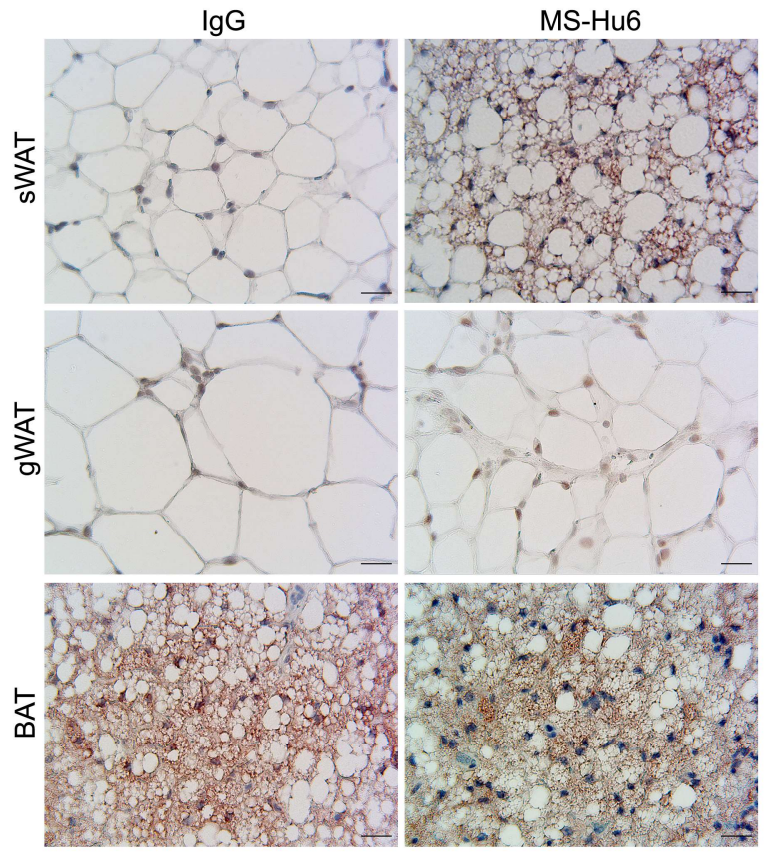

$\mathrm{E}$

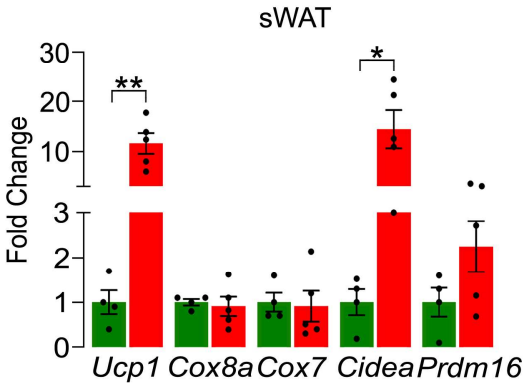

B
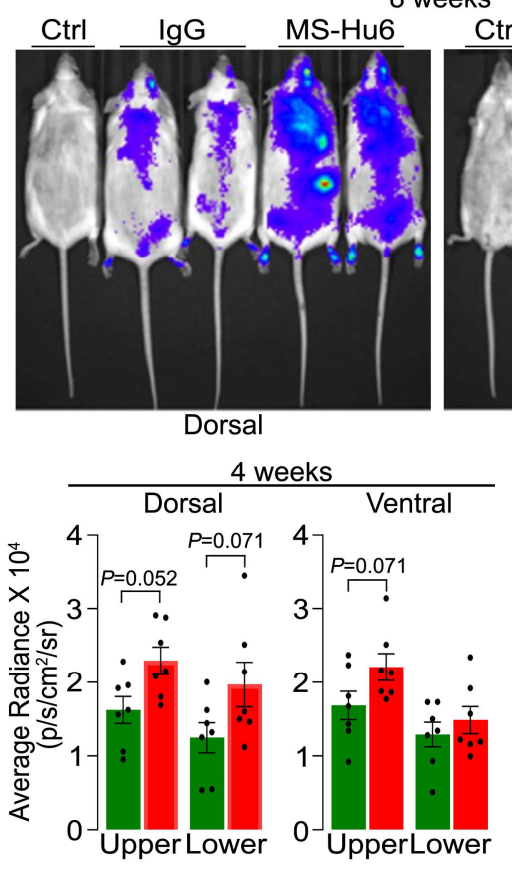

D
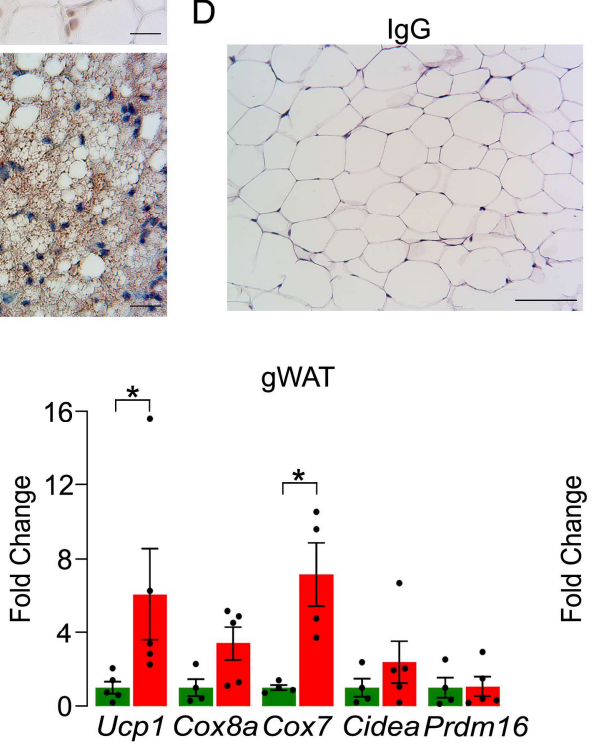

8 weeks

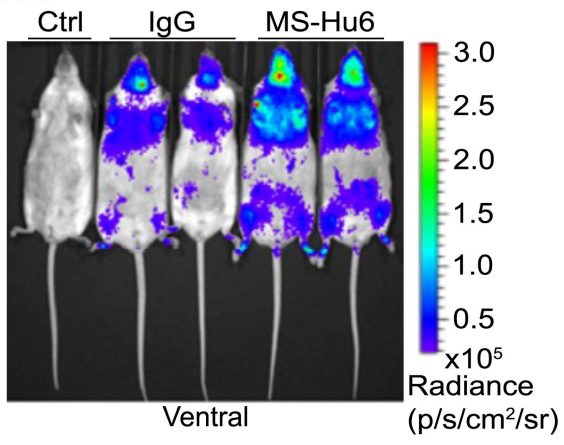

(p/s/cm²/sr)

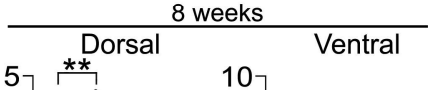

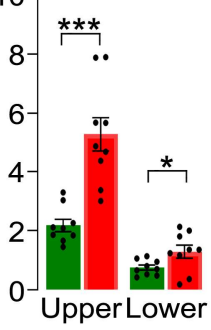
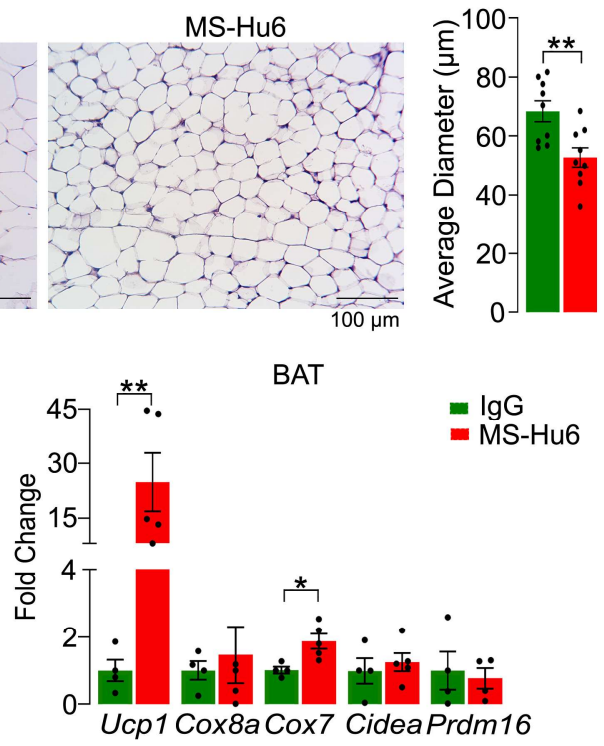
bioRxiv preprint doi: https://doi.org/10.1101/2022.02.28.482279; this version posted March 2, 2022. The copyright holder for this preprint (which was not certified by peer review) is the author/funder, who has granted bioRxiv a license to display the preprint in perpetuity. It is made available under aCC-BY 4.0 International license.

Figure 3

A
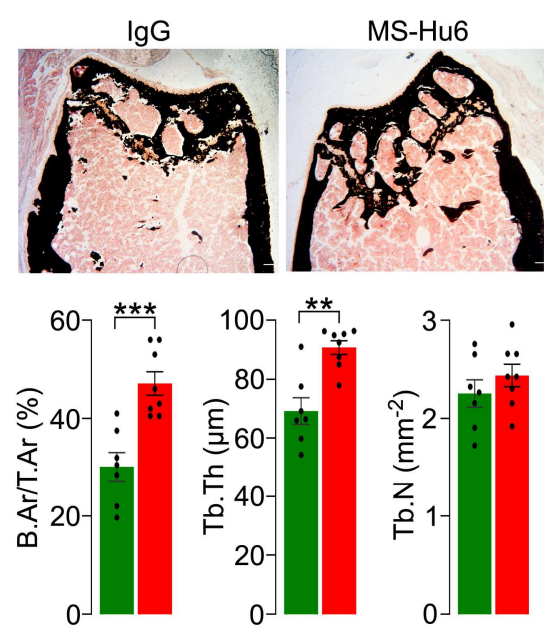

B

G
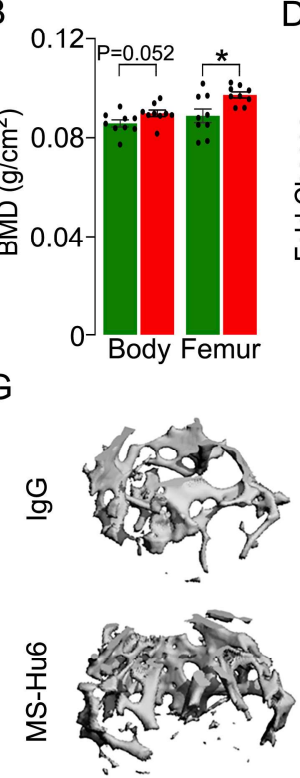

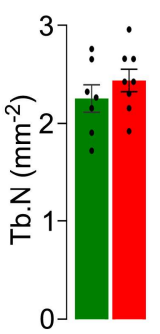

D

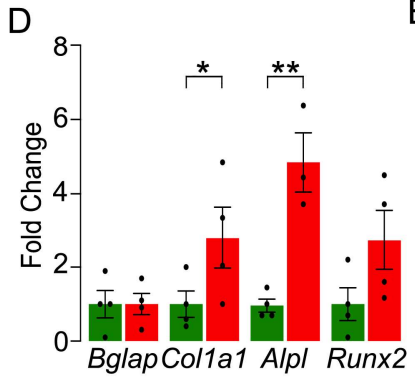

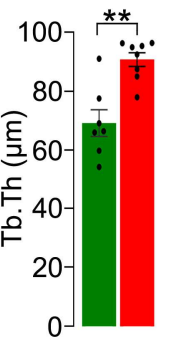

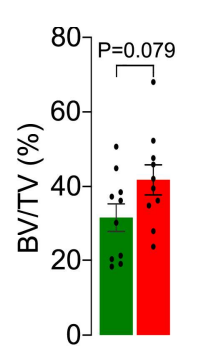

C
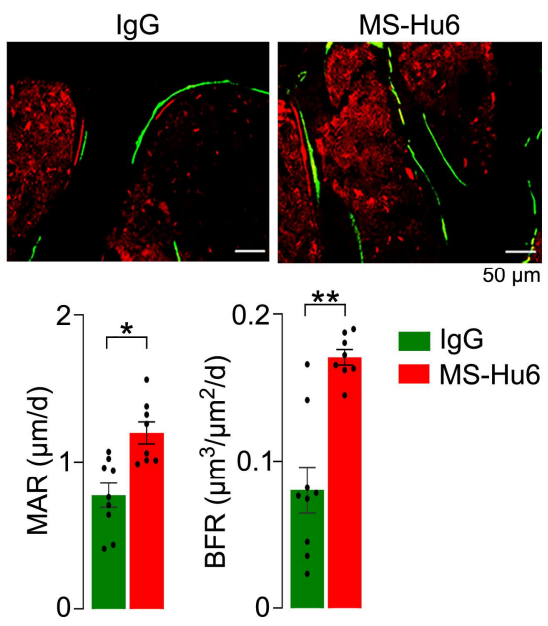

E

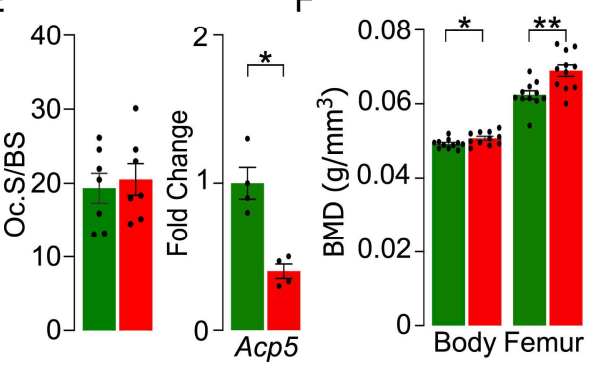

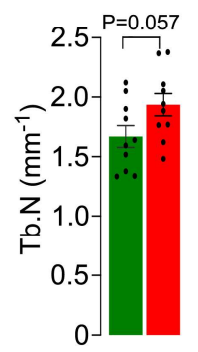
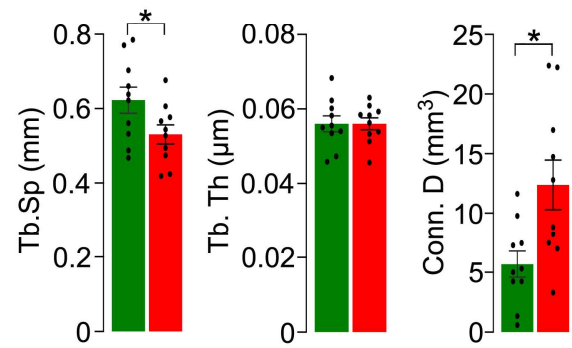
bioRxiv preprint doi: https://doi.org/10.1101/2022.02.28.482279; this version posted March 2, 2022. The copyright holder for this preprint (which was not certified by peer review) is the author/funder, who has granted bioRxiv a license to display the preprint in perpetuity. It is made available under aCC-BY 4.0 International license.

Figure 4

A

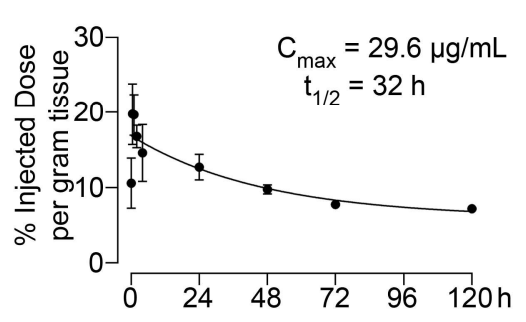

C

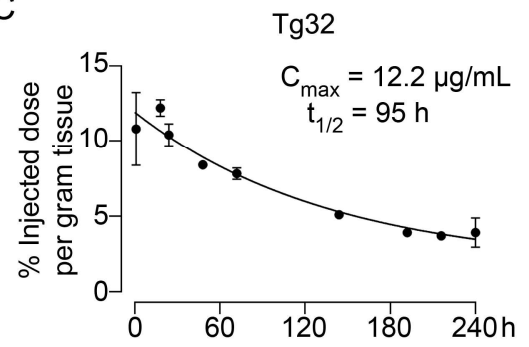

E

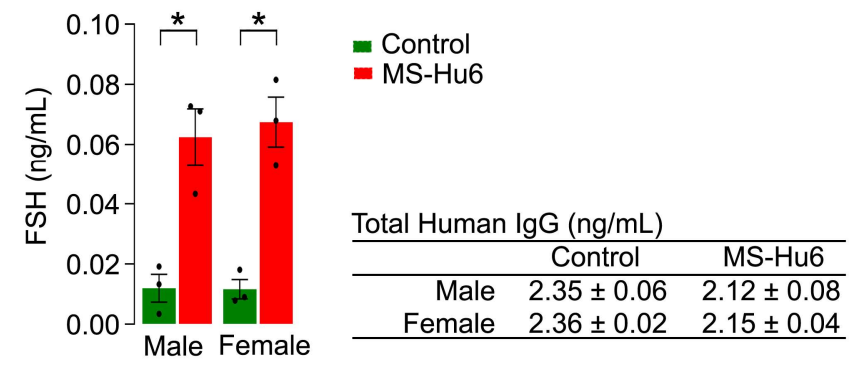

B

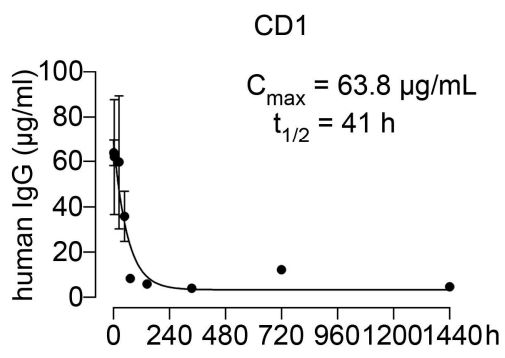

D

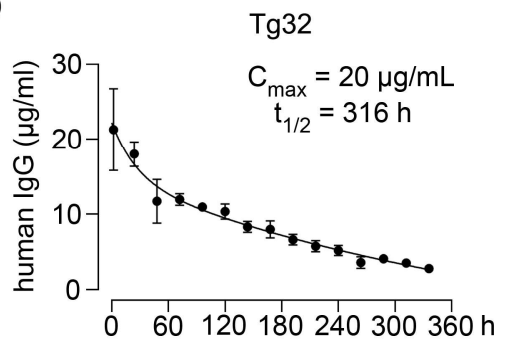


bioRxiv preprint doi: https://doi.org/10.1101/2022.02.28.482279; this version posted March 2, 2022. The copyright holder for this preprint (which was not certified by peer review) is the author/funder, who has granted bioRxiv a license to display the preprint in perpetuity. It is made available under aCC-BY 4.0 International license.

Figure 5

A

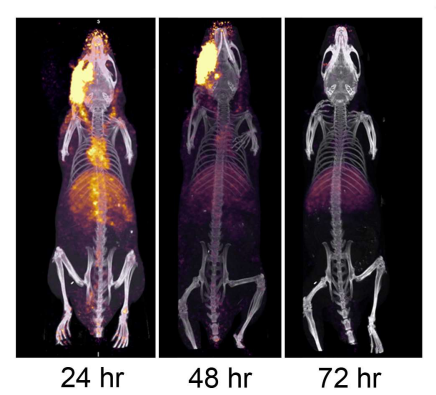

C

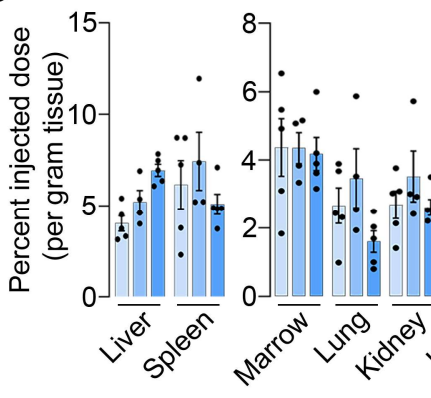

$\mathrm{F}$

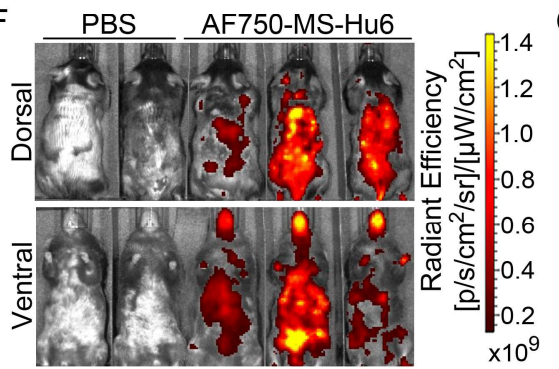

$\mathrm{H}$
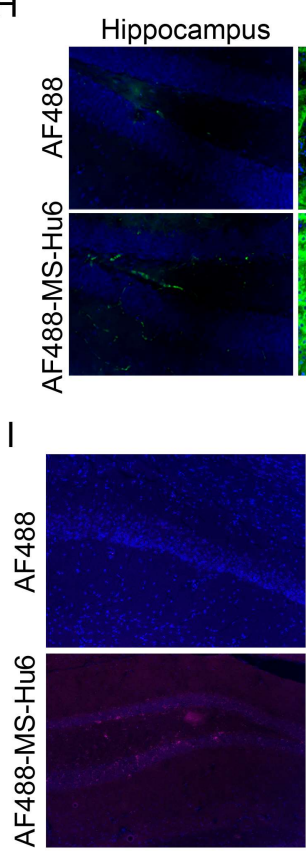

B

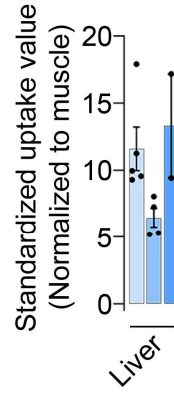

$\left[\begin{array}{l}8 \\ 6 \\ 4 \\ 2 \\ 0\end{array}\right.$

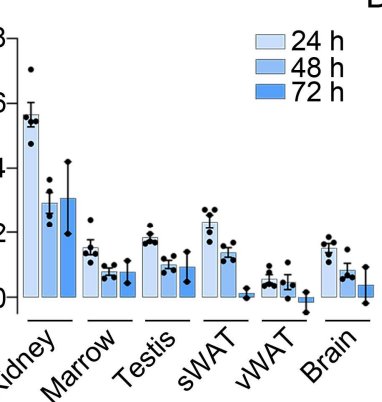

E

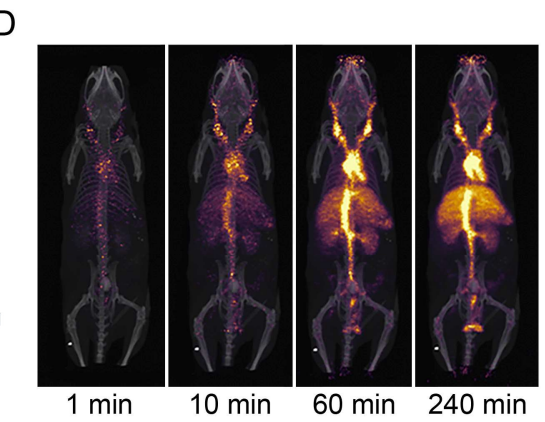

E
$1 \mathrm{~min} \quad 10 \mathrm{~min} \quad 60 \mathrm{~min} 240 \mathrm{~min}$

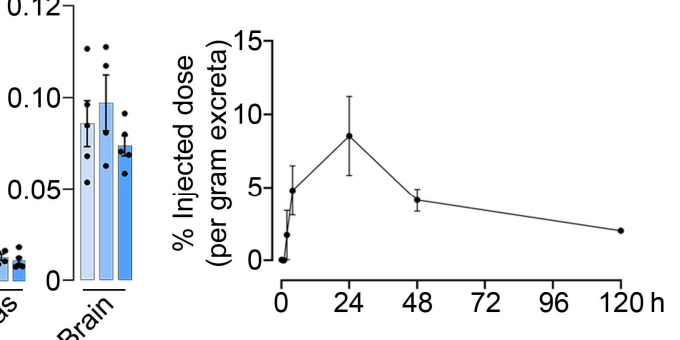

G G

$\square 24 \mathrm{~h}$

$-72 \mathrm{~h}$
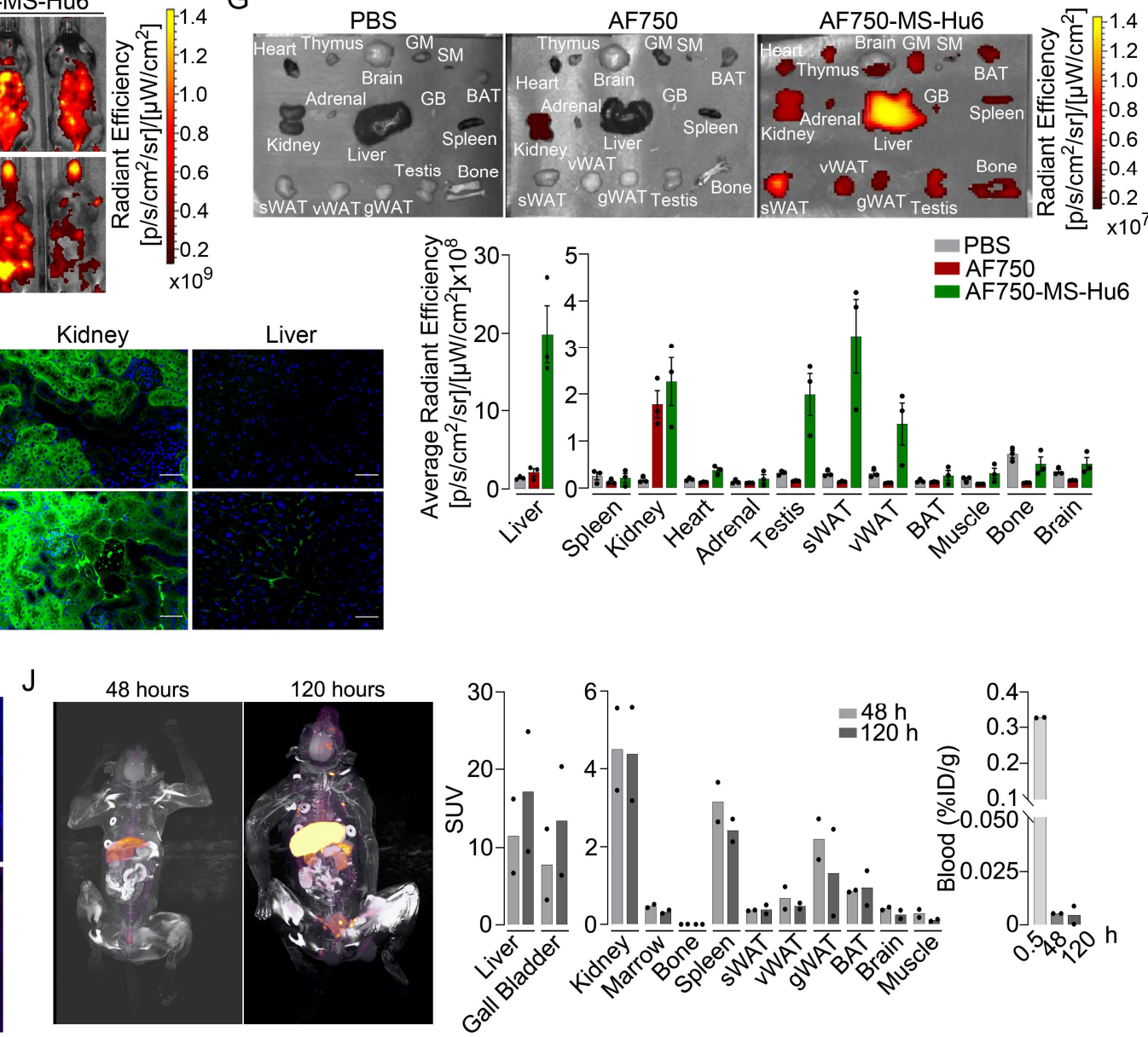
bioRxiv preprint doi: https://doi.org/10.1101/2022.02.28.482279; this version posted March 2, 2022. The copyright holder for this preprint (which was not certified by peer review) is the author/funder, who has granted bioRxiv a license to display the preprint in perpetuity. It is made available under aCC-BY 4.0 International license.

A
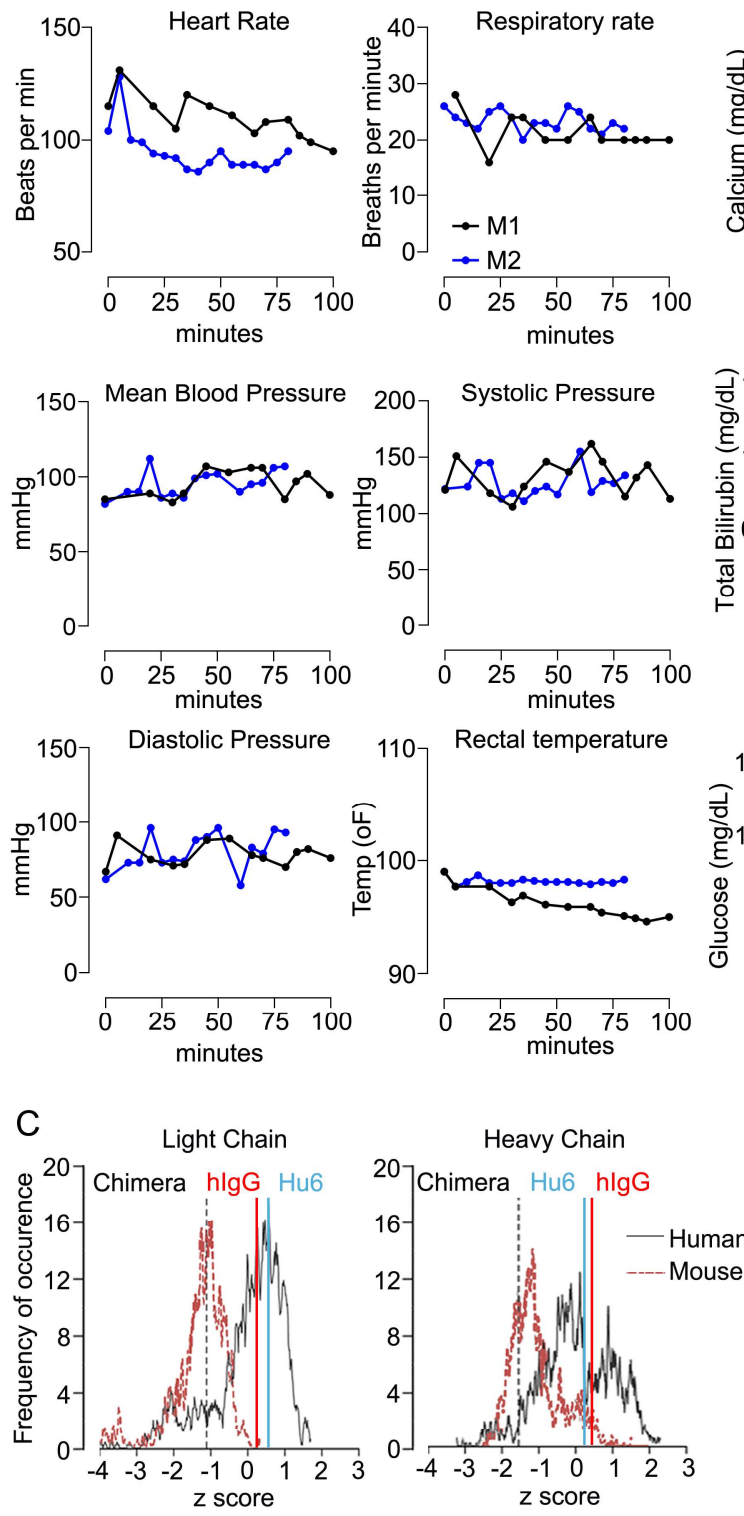

B
Figure 6
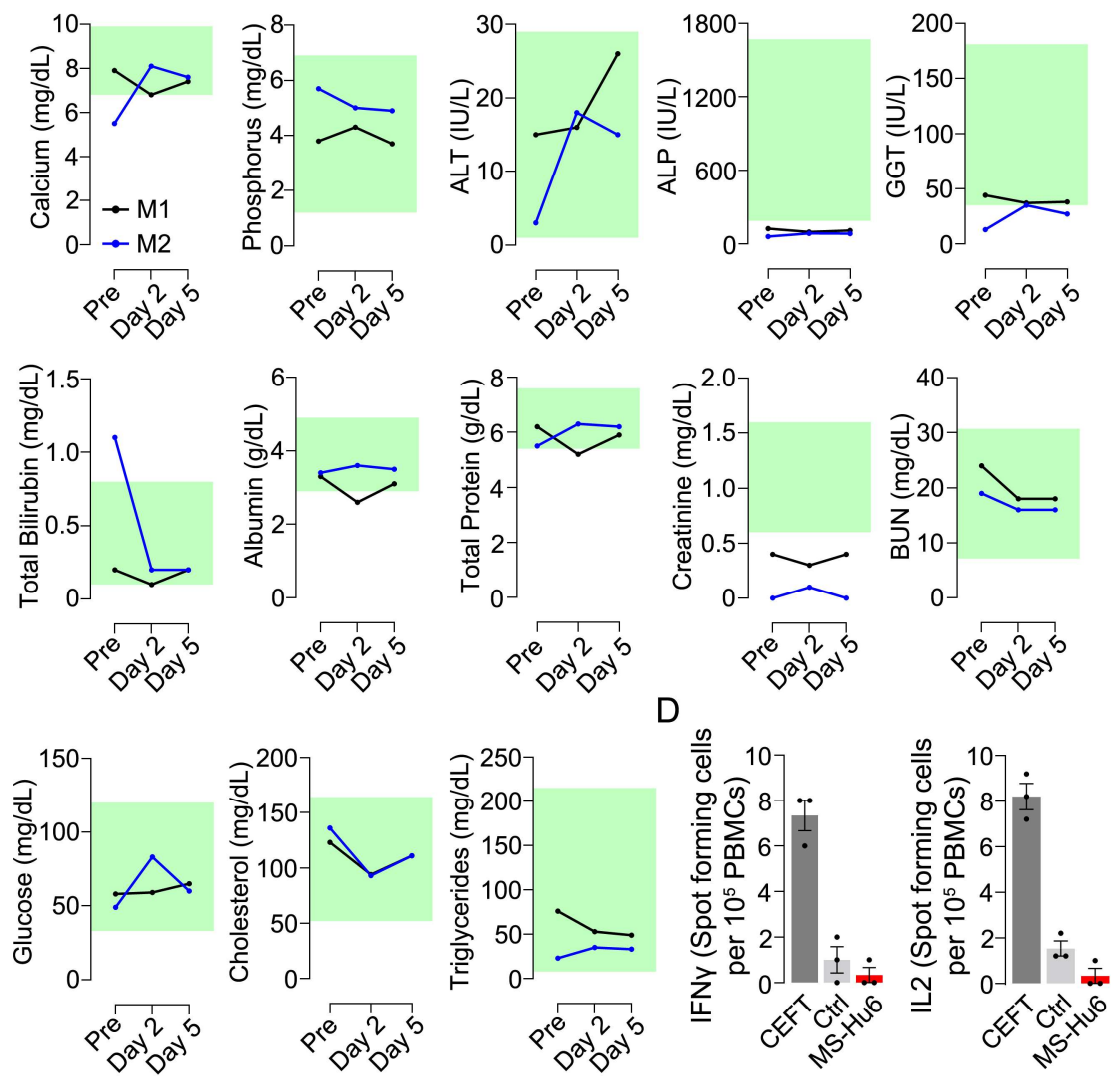

$\mathrm{E}$

\begin{tabular}{lcc}
\hline Z-score & $\mathrm{V}_{\mathrm{H}}$ & $\mathrm{V}_{\mathrm{L}}$ \\
\hline human IgG 1 & 0.563 & 0.085 \\
MS-Hu6 & 0.178 & 0.331 \\
Chimera & -1.478 & -1.118 \\
Bevacizumab & 0.652 & 0.673 \\
Trastuzumab & 0.967 & 0.511 \\
Atezolizumab & 1.585 & 0.700 \\
Adalimumab & 0.884 & 0.748 \\
Alirocumab & 0.953 & -0.125 \\
Canakinumab & 1.435 & -0.827 \\
\hline
\end{tabular}

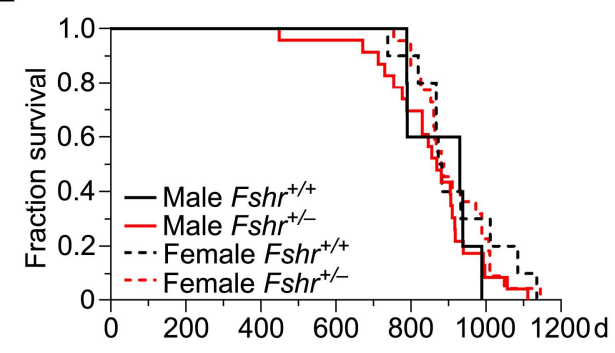


bioRxiv preprint doi: https://doi.org/10.1101/2022.02.28.482279; this version posted March 2, 2022. The copyright holder for this preprint (which was not certified by peer review) is the author/funder, who has granted bioRxiv a license to display the preprint in perpetuity. It is made available under aCC-BY 4.0 International license.

\section{Figure 7}
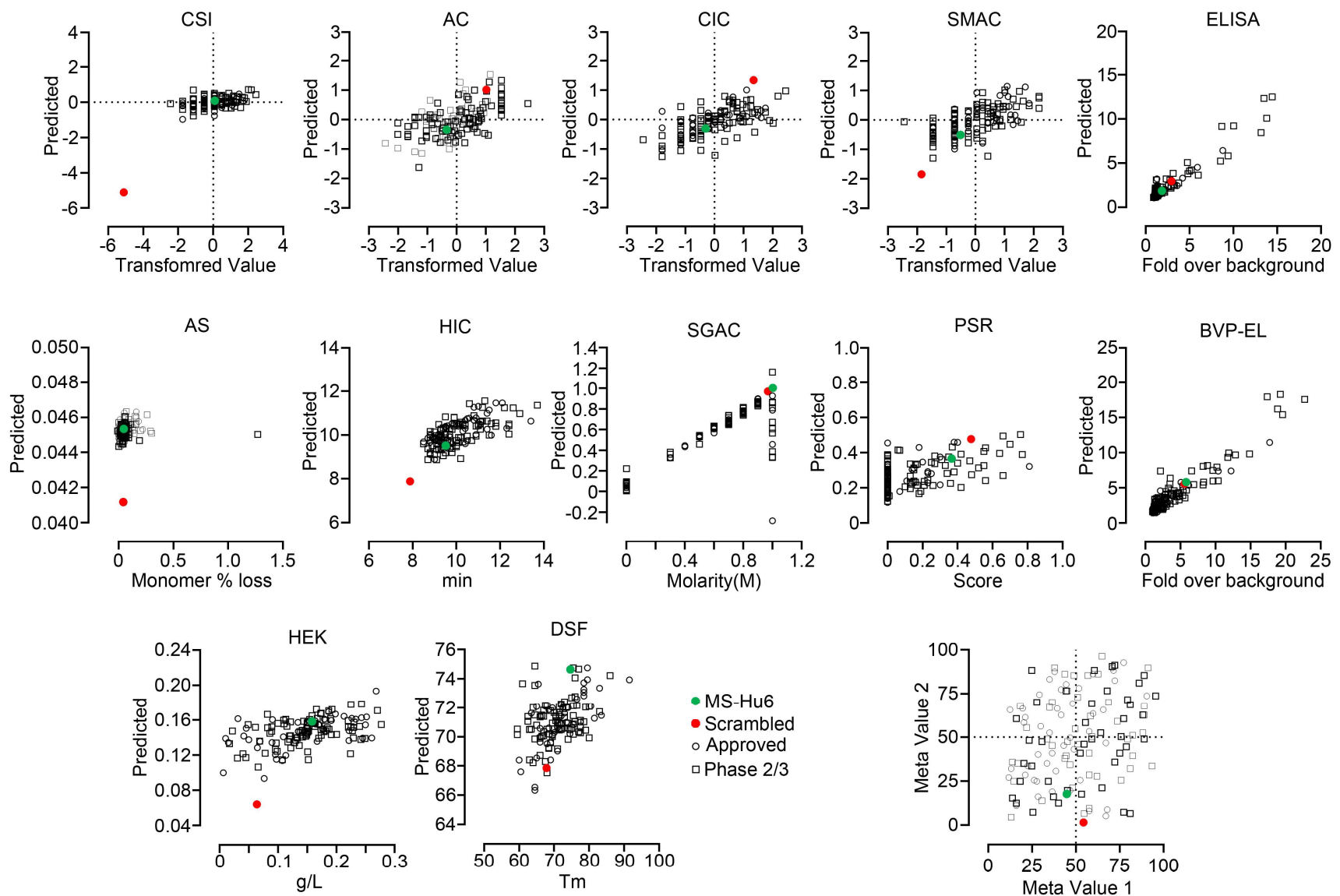

\begin{tabular}{|c|c|c|c|c|c|c|c|}
\hline \multirow[b]{2}{*}{ Assays } & \multirow[b]{2}{*}{ Abbrev. } & \multirow{2}{*}{$\begin{array}{l}\text { Physicochemical } \\
\text { Property }\end{array}$} & \multirow[b]{2}{*}{ Thres. } & \multicolumn{2}{|c|}{ MS-Hu6 } & \multicolumn{2}{|c|}{ Scrambled } \\
\hline & & & & Value & Output & Value & Output \\
\hline Clone Self-interaction by Bio-layer Interferometry & CSI-BLI & Self-Interaction & 0.28 & 0.09 & Safe & -5.97 & Safe \\
\hline Affinity Capture & $\mathrm{AC}$ & Self-Interaction & 0.61 & -0.34 & Safe & 1.02 & Unsafe \\
\hline Cross-interaction Chromatography & $\mathrm{ClC}$ & Cross-Interaction & 0.47 & -0.30 & Safe & 1.41 & Unsafe \\
\hline Stand-up Monolayer Adsorption Chromatography & SMAC & Cross-Interaction & 0.67 & -0.51 & Safe & -1.58 & Safe \\
\hline Enyzme-linked Immunosorbent Assay & ELISA & Non-Specific Binding & 2.36 & 1.86 & Safe & 2.98 & Safe \\
\hline Accelerated Stability & AS & Shelf Life & 0.05 & 0.05 & Safe & 0.04 & Safe \\
\hline Hydrophobic Interaction Chromatography & $\mathrm{HIC}$ & Hydrophobic Interaction & 11.2 & 9.5 & Safe & 8.1 & Safe \\
\hline Salt Gradient Affinity Capture & SGAC & Hydrophobic Interaction & 865 & 1003 & Safe & 969 & Safe \\
\hline Poly-specificity Reagent & PSR & Poly-Specificity & 0.36 & 0.37 & Safe & 0.46 & Unsafe \\
\hline Baculovirus particle ELISA & BVP-EL & Plasma Clearance & 4.99 & 5.82 & Safe & 5.27 & Safe \\
\hline Expression titer in HEK cells & HEK & Antibody Titer & 163 & 158 & Safe & 15 & Unsafe \\
\hline Differential Scanning Fluorescence & DSF & Melting Temperature & $73.7^{\circ} \mathrm{C}$ & $74.6^{\circ} \mathrm{C}$ & Safe & $67.0^{\circ} \mathrm{C}$ & Unsafe \\
\hline
\end{tabular}


bioRxiv preprint doi: https://doi.org/10.1101/2022.02.28.482279; this version posted March 2, 2022. The copyright holder for this preprint (which was not certified by peer review) is the author/funder, who has granted bioRxiv a license to display the preprint in perpetuity. It is made available under aCC-BY 4.0 International license.

\section{Figure 8}

A $\mathrm{pH} 3$

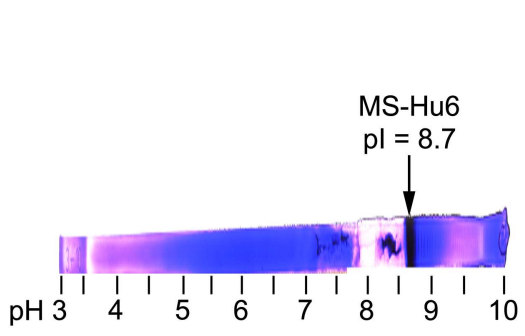

B

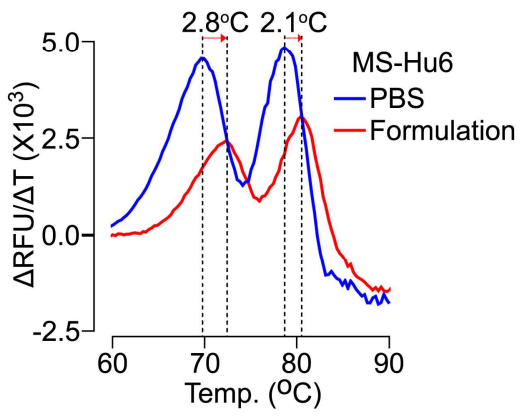

C

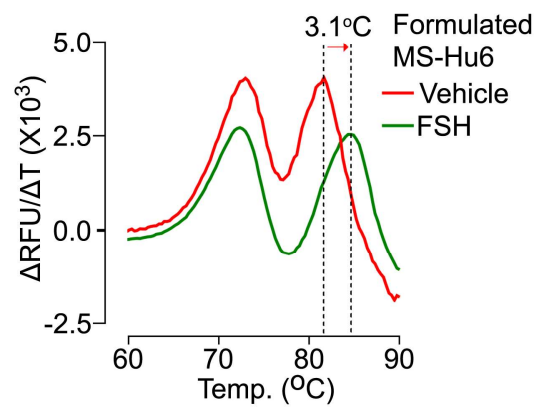

D Self-Interaction Chromatography
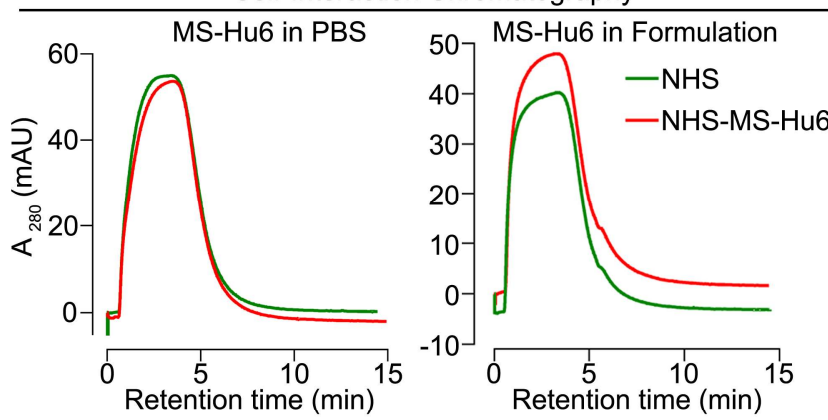

F

Hydrophobic Interaction Chromatography

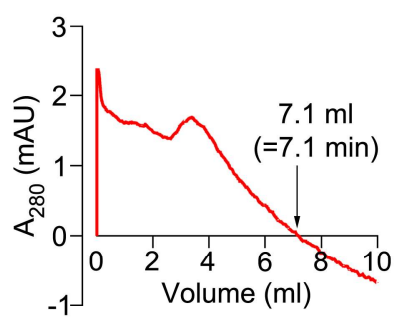

G

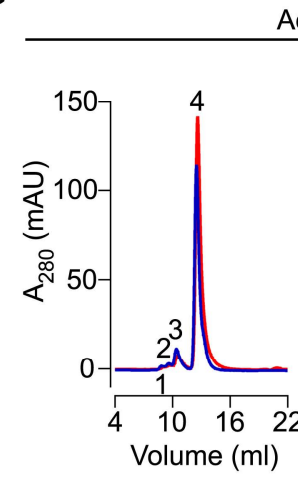

Accelerated Stability

MS-Hu6 in PBS

\begin{tabular}{|c|c|c|c|c|}
\hline Peak & $4^{\circ} \mathrm{C}$ & $37^{\circ} \mathrm{C}$ & $50^{\circ} \mathrm{C}$ & Freeze-thaw \\
\hline 1 & $0.01 \%$ & $0.70 \%$ & $0.00 \%$ & $0.10 \%$ \\
\hline 2 & $0.21 \%$ & $0.22 \%$ & $0.00 \%$ & $0.01 \%$ \\
\hline 3 & $0.11 \%$ & $2.37 \%$ & $1.28 \%$ & $12.75 \%$ \\
\hline 4 & $99.6 \%$ & $96.4 \%$ & $98.7 \%$ & $87.2 \%$ \\
\hline \multicolumn{5}{|c|}{ MS-Hu6 in Formulation } \\
\hline Peak & $4^{\circ} \mathrm{C}$ & $37^{\circ} \mathrm{C}$ & $50^{\circ} \mathrm{C}$ & Freeze-thaw \\
\hline 1 & $0.00 \%$ & $0.03 \%$ & $0.02 \%$ & $0.17 \%$ \\
\hline 2 & $0.13 \%$ & $0.27 \%$ & $0.91 \%$ & $0.00 \%$ \\
\hline 3 & $0.18 \%$ & $1.43 \%$ & $0.37 \%$ & $0.23 \%$ \\
\hline 4 & $99.7 \%$ & $98.2 \%$ & $98.7 \%$ & $99.6 \%$ \\
\hline
\end{tabular}

Cross-Interaction Chromatography
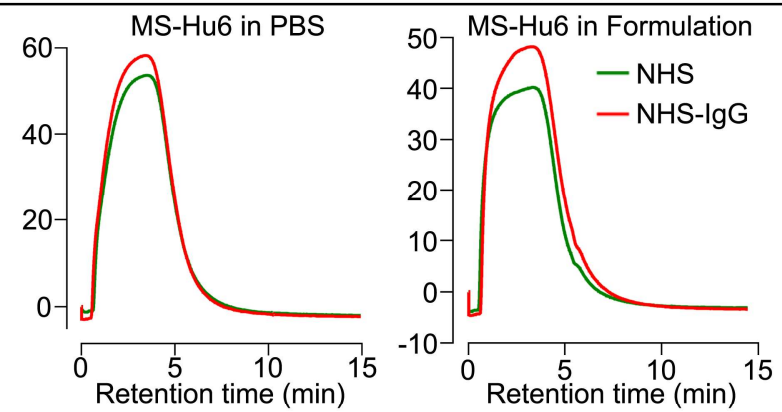

$\mathrm{H}$

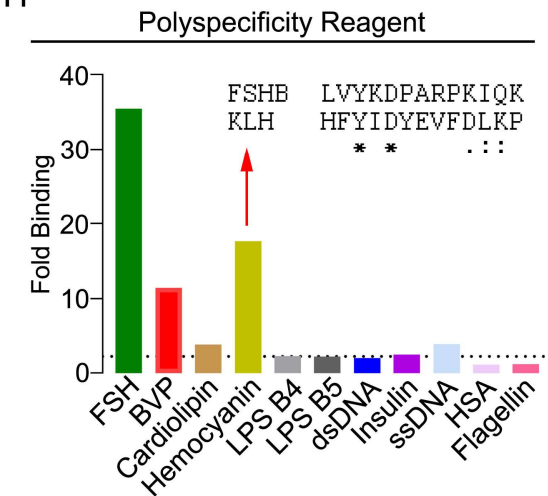




\section{Supplementary Figure 1}
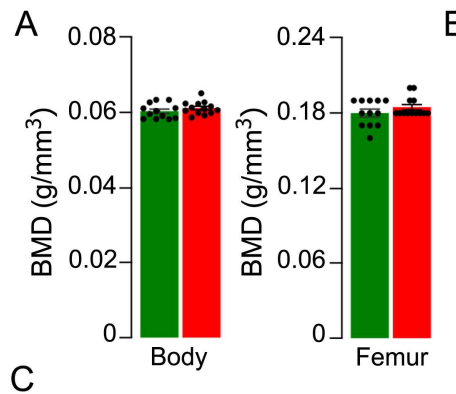

B
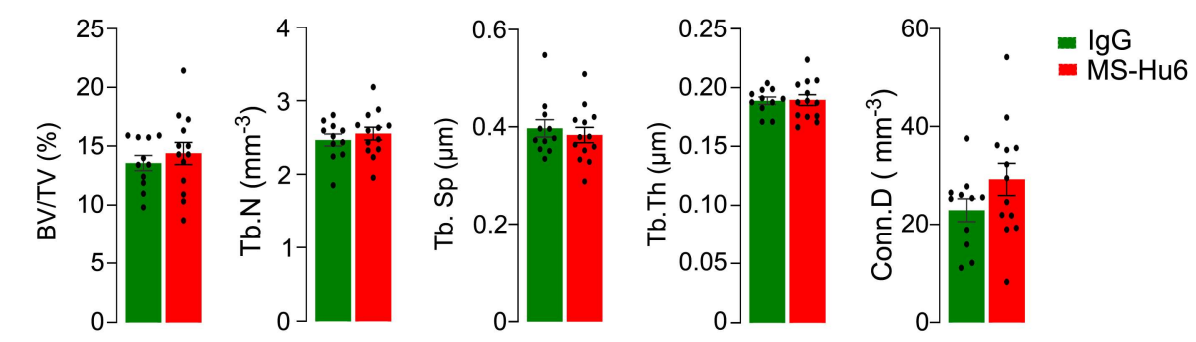